\title{
A new inorganic atmospheric aerosol phase equilibrium model (UHAERO)
}

\author{
N. R. Amundson ${ }^{1}$, A. Caboussat ${ }^{1}$, J. W. He ${ }^{1}$, A. V. Martynenko ${ }^{1}$, V. B. Savarin ${ }^{2}$, J. H. Seinfeld ${ }^{3}$, and K. Y. Yoo ${ }^{4}$ \\ ${ }^{1}$ Department of Mathematics, University of Houston, Houston, USA \\ ${ }^{2}$ Ecole Nationale Supérieure de Techniques Avancées, Paris, France \\ ${ }^{3}$ Departments of Chemical Engineering and Environmental Science and Engineering, California Institute of Technology, \\ Pasadena, USA \\ ${ }^{4}$ Department of Chemical Engineering, Seoul National University of Technology, Seoul, Korea
}

Received: 17 August 2005 - Published in Atmos. Chem. Phys. Discuss.: 28 September 2005

Revised: 23 December 2005 - Accepted: 7 February 2006 - Published: 28 March 2006

\begin{abstract}
A variety of thermodynamic models have been developed to predict inorganic gas-aerosol equilibrium. To achieve computational efficiency a number of the models rely on a priori specification of the phases present in certain relative humidity regimes. Presented here is a new computational model, named UHAERO, that is both efficient and rigorously computes phase behavior without any a priori specification. The computational implementation is based on minimization of the Gibbs free energy using a primal-dual method, coupled to a Newton iteration. The mathematical details of the solution are given elsewhere. The model computes deliquescence behavior without any a priori specification of the relative humidities of deliquescence. Also included in the model is a formulation based on classical theory of nucleation kinetics that predicts crystallization behavior. Detailed phase diagrams of the sulfate/nitrate/ammonium/water system are presented as a function of relative humidity at $298.15 \mathrm{~K}$ over the complete space of composition.
\end{abstract}

\section{Introduction}

The inorganic constituents of atmospheric particles typically consist of electrolytes of ammonium, sodium, calcium, sulfate, nitrate, chloride, carbonate, etc. The phase state of such a mixture at a given temperature and relative humidity will tend to thermodynamic equilibrium with the gas phase. A variety of thermodynamic models have been developed to predict inorganic gas-aerosol equilibrium (Table 1; see also Zhang et al., 2000). The models can be distinguished based on two general features: (1) the method of computing activity coefficients of the aerosol-phase species; and (2) the numeri-

Correspondence to: J. H. Seinfeld

(seinfeld@caltech.edu) cal technique that is used to determine the equilibrium state. Obtaining the equilibrium composition of the aerosol is challenging because multiple liquid and/or solid phases can exist, depending on the chemical composition, ambient relative humidity $(R H)$, and temperature.

One may calculate the composition of the aerosol either by solving the set of nonlinear algebraic equations derived from mass balances and chemical equilibrium or by performing a direct minimization of the Gibbs free energy. Direct minimization of the Gibbs free energy has tended to be computationally demanding, making its use in large-scale atmospheric models unattractive, since the thermodynamic model must, in principle, be implemented in each grid cell at each time step. The most challenging aspect of the numerical determination of the equilibrium is the prediction of the partitioning of the inorganic components between aqueous and solid phases in the aerosol. For computational efficiency, a number of the current methods (see Table 1) rely on a priori specification of the presence of phases at a certain relative humidity and overall composition; two models that fall into this category are SCAPE2 and ISORROPIA, both of which employ divided $R H$ and composition domains in which only certain equilibria are assumed to hold. While these assumptions greatly facilitate numerical determination of the equilibrium, they lead to approximations in the phase diagram of the system that may be undesirable (Ansari and Pandis, 1999). What is ultimately needed is an efficient computational model for the equilibrium partitioning of aerosol components between aqueous and solid phases that does not rely on a priori knowledge of the presence of certain phases at a given relative humidity and overall composition.

The physical state of the atmospheric aerosol phase depends on the $R H$ history of the particle. As $R H$ increases from a value at which the particles are dry, crystalline

Published by Copernicus GmbH on behalf of the European Geosciences Union. 
Table 1. Gas-aerosol equilibrium models ${ }^{1}$.

\begin{tabular}{|c|c|c|c|}
\hline Model name ${ }^{2}$ & $\begin{array}{l}\text { System } \\
\text { addressed }\end{array}$ & $\begin{array}{l}\text { Activity } \\
\text { method }^{3}\end{array}$ & Computational method \\
\hline SCAPE2 & $\begin{array}{l}\mathrm{NH}_{4}^{+} / \mathrm{Na}^{+} / \mathrm{Ca}^{2+} / \\
\mathrm{Mg}^{+} / \mathrm{K}^{+} / \mathrm{NO}_{3}^{-} / \\
\mathrm{SO}_{4}^{-2} / \mathrm{Cl}^{-} / \mathrm{CO}_{3}^{2-}\end{array}$ & $\begin{array}{l}\text { Choice of Bromley, KM, } \\
\text { Pitzer @ } 298.15 \mathrm{~K} . \mathrm{ZSR} \\
\text { for water content. }\end{array}$ & $\begin{array}{l}\text { Classifies problem into one of several subdomains. Nonlinear } \\
\text { equations solved by iterative bisection. Each salt assumed to } \\
\text { deliquesce at its own DRH. }\end{array}$ \\
\hline ISORROPIA & $\begin{array}{l}\mathrm{NH}_{4}^{+} / \mathrm{Na}^{+} / \mathrm{NO}_{3}^{-} / \\
\mathrm{SO}_{4}^{-2} / \mathrm{Cl}^{-}\end{array}$ & $\begin{array}{l}\text { Bromle @ } 298.15 \mathrm{~K} . \mathrm{ZSR} \\
\text { for water content. }\end{array}$ & $\begin{array}{l}\text { Classifies problem into one of several subdomains. Nonlinear } \\
\text { equations solved by iterative bisection. Mixture assumed to } \\
\text { deliquesce at } R H>\text { lowest DRH of all salts present. }\end{array}$ \\
\hline EQUISOLV II & $\begin{array}{l}\mathrm{NH}_{4}^{+} / \mathrm{Na}^{+} / \mathrm{Ca}^{2+} / \\
\mathrm{Mg}^{+} / \mathrm{K}^{+} / \mathrm{NO}_{3}^{-} /\end{array}$ & $\begin{array}{l}\text { Bromley }{ }^{4} \text {. ZSR for water } \\
\text { content. }\end{array}$ & $\begin{array}{l}\text { Nonlinear equations solved one at a time then iterated to to } \\
\text { convergence. }\end{array}$ \\
\hline GFEMN & $\begin{array}{l}\mathrm{SO}_{4}^{-2} / \mathrm{Cl}^{-} / \mathrm{CO}_{3}^{2-} \\
\mathrm{NH}_{4}^{+} / \mathrm{Na}^{+} / \mathrm{NO}_{3}^{-} / \\
\mathrm{SO}_{4}^{-2} / \mathrm{Cl}^{-}\end{array}$ & $\begin{array}{l}\text { PSC @ } 298.15 \mathrm{~K} . \mathrm{ZSR} \\
\text { for water content. }\end{array}$ & Iterative Gibbs free energy minimization. \\
\hline $\begin{array}{l}\text { AIM2 (Model } \\
\text { III) }\end{array}$ & $\begin{array}{l}\mathrm{NH}_{4}^{+} / \mathrm{Na}^{+} / \mathrm{NO}_{3}^{-} / \\
\mathrm{SO}_{4}^{-2} / \mathrm{Cl}^{-}\end{array}$ & $\begin{array}{l}\text { PSC @ } 298.15 \mathrm{~K} . \mathrm{ZSR} \\
\text { for water content. }\end{array}$ & Iterative Gibbs free energy minimization. \\
\hline EQSAM & $\begin{array}{l}\mathrm{NH}_{4}^{+} / \mathrm{Na}^{+} / \mathrm{K}^{+} / \\
\mathrm{Ca}^{2+} / \mathrm{Mg}^{+} / \mathrm{NO}_{3}^{-} / \\
\mathrm{SO}_{4}^{-2} / \mathrm{Cl}^{-}\end{array}$ & $\begin{array}{l}\text { Parameterization of ac- } \\
\text { tivity coefficient-RH rela- } \\
\text { tionship. }\end{array}$ & No iterations required. \\
\hline MESA & $\begin{array}{l}\text { solid-liquid: } \\
\mathrm{NH}_{4}^{+} / \mathrm{Na}^{+} / \mathrm{Ca}^{2+} / \\
\mathrm{NO}_{3}^{-} / \mathrm{SO}_{4}^{-2} / \mathrm{Cl}^{-}\end{array}$ & $\begin{array}{l}\text { Choice of PSC, } \\
\text { MTEMd/KM, Brom- } \\
\text { ley @ 298.15 K. ZSR for } \\
\text { water content. }\end{array}$ & $\begin{array}{l}\text { Simultaneous iteration of all solid-liquid equilibria using } \\
\text { pseudo-transient continuation method. }\end{array}$ \\
\hline ADDEM & $\begin{array}{l}\mathrm{NH}_{4}^{+} / \mathrm{Na}^{+} / \mathrm{NO}_{3}^{-} / \\
\mathrm{SO}_{4}^{-2} / \mathrm{Cl}^{-}\end{array}$ & $\begin{array}{l}\text { PSC. Clegg solvent activ- } \\
\text { ity model for water con- } \\
\text { tent. }\end{array}$ & $\begin{array}{l}\text { FFSQP (Fast Fortran Sequential Quadratic Programming) to } \\
\text { minimize Gibbs free energy. }\end{array}$ \\
\hline UHAERO & $\begin{array}{l}\mathrm{NH}_{4}^{+} / \mathrm{Na}^{+} / \mathrm{NO}_{3}^{-} / \\
\mathrm{SO}_{4}^{-2} / \mathrm{Cl}^{-}\end{array}$ & $\begin{array}{l}\text { Choice of PSC, ExUNI- } \\
\text { QUAC. }\end{array}$ & Minimization of Gibbs free Energy (see text). \\
\hline
\end{tabular}

1 Table adapted from Zaveri et al. (2005b).

2 SCAPE2 (Kim et al., 1993a,b; Kim and Seinfeld, 1995; Meng et al., 1995); ISORROPIA (Nenes et al., 1998); EQUISOLV II (Jacobson et al., 1996; Jacobson, 1999); GFEMN (Ansari and Pandis, 1999); AIM2 (Clegg et al., 1998a,b; Wexler and Clegg, 2002); EQSAM (Metzger et al., 2002; Trebs et al., 2005); MESA (Zaveri et al., 2005a); ADDEM (Topping et al., 2005)

3 Bromley (Bromley, 1973); KM (Kusik and Meissner, 1978); Pitzer (Pitzer and Mayorga, 1973); PSC (Pitzer and Simonson, 1986; Clegg et al., 1992, 1998a,b; Wexler and Clegg, 2002); MTEM (Zaveri et al., 2005b); ZSR (Stokes and Robinson, 1966); ExUNIQAC (Thomsen and Rasmussen, 1999)

${ }^{4}$ Binary activity coefficients for the electrolytes in the $\mathrm{NH}_{4}^{+} / \mathrm{Na}^{+} / \mathrm{NO}_{3}^{-} / \mathrm{SO}_{4}^{-2} / \mathrm{Cl}^{-}$system are temperature dependent, while they are fixed at $298.15 \mathrm{~K}$ for the $\mathrm{Ca}^{2+} / \mathrm{Mg}^{+} / \mathrm{K}^{+} / \mathrm{NO}_{3}^{-} / \mathrm{SO}_{4}^{-2} / \mathrm{Cl}^{-} / \mathrm{CO}_{3}^{2-}$ system

particles spontaneously take up water at the deliquescence $R H$ (DRH) transforming into aqueous droplets containing dissolved ions; as $R H$ decreases from a value above the $\mathrm{DRH}$, aqueous particles do not crystallize (effloresce) until the crystallization $R H(\mathrm{CRH})$ is reached. Between the DRH and the CRH, particles may be either crystalline or aqueous, depending on their $R H$ history. The upper and lower branches of the particle diameter versus $R H$ behavior constitute a hysteresis loop, in which crystalline particles below the DRH follow the lower ascending branch and aqueous particles above the $\mathrm{CRH}$ follow the upper descend- ing branch. Current aerosol thermodynamic models account for the deliquescence and efflorescence hysteresis based on a priori knowledge of the presence of solid phases at a certain relative humidity and overall composition. They either assume crystallization of a solid in a multicomponent solution once the $R H$ drops below the DRH of the solid salt, or neglect solidification altogether. What is needed is a model that predicts both deliquescence and crystallization based purely upon the thermodynamics.

The goal of this paper is to present the results of application of a new inorganic gas-aerosol equilibrium model 
(UHAERO) that is based on a computationally efficient minimization of the Gibbs free energy, and in which no a priori assumptions are made about the phases present at any particular relative humidity and temperature. Also included in the model is a formulation based on classical theory of nucleation kinetics that simulates the transformation from a metastable phase into a thermodynamically more favorable phase. This physically consistent theory predicts explicitly the physical state of the particle and the deliquescence and efflorescence hysteresis. The model is capable of representing the phase transition and state of atmospheric aerosols over the full range of relative humidity regimes.

The next section summarizes the minimization problem; its mathematical foundation and computational implementation are presented elsewhere (Amundson et al., 2005, 2006). The third section discusses the determination of phase transitions, such as deliquescence and crystallization. The remainder of the paper is devoted to computation of aerosol phase equilibria in the sulfate/nitrate/ammonium system.

\section{Determination of equilibrium}

The multicomponent chemical equilibrium for a closed gasaerosol system at constant temperature and pressure and a specified elemental abundance is the solution to the following problem arising from the minimization of the Gibbs free energy, $G$,

$\operatorname{Min} G\left(\boldsymbol{n}_{l}, \boldsymbol{n}_{g}, \boldsymbol{n}_{s}\right)=\boldsymbol{n}_{g}^{T} \boldsymbol{\mu}_{g}+\boldsymbol{n}_{l}^{T} \boldsymbol{\mu}_{l}+\boldsymbol{n}_{s}^{T} \boldsymbol{\mu}_{s}$,

subject to $\boldsymbol{n}_{g}>\mathbf{0}, \boldsymbol{n}_{l}>\mathbf{0}, \boldsymbol{n}_{s} \geq \mathbf{0}$, and

$\boldsymbol{A}_{g} \boldsymbol{n}_{g}+\boldsymbol{A}_{l} \boldsymbol{n}_{l}+\boldsymbol{A}_{s} \boldsymbol{n}_{s}=\boldsymbol{b}$,

where $\boldsymbol{n}_{g}, \boldsymbol{n}_{l}, \boldsymbol{n}_{s}$ are the concentration vectors in gas, liquid, and solid phases, respectively, $\boldsymbol{\mu}_{g}, \boldsymbol{\mu}_{l}, \boldsymbol{\mu}_{s}$ are the corresponding chemical potential vectors, $\boldsymbol{A}_{g}, \boldsymbol{A}_{l}, \boldsymbol{A}_{s}$ are the component-based formula matrices, and $\boldsymbol{b}$ is the componentbased feed vector. Condition (2) expresses the fact, for example, that in calculating the partition of sulfate between aqueous and solid phases the total sulfate concentration is conserved, while maintaining a charge balance in solution.

The chemical potential vectors are given by

$\boldsymbol{\mu}_{g}=\boldsymbol{\mu}_{g}^{0}+R T \ln \boldsymbol{a}_{g}$,

$\boldsymbol{\mu}_{l}=\boldsymbol{\mu}_{l}^{0}+R T \ln \boldsymbol{a}_{l}$,

$\boldsymbol{\mu}_{s}=\boldsymbol{\mu}_{s}^{0}$,

where $R$ is the universal gas constant, $T$ is the system temperature, $\boldsymbol{\mu}_{g}^{0}$ and $\boldsymbol{\mu}_{l}^{0}$ are the standard chemical potentials of gas and liquid species, respectively, and $\boldsymbol{a}_{g}$ and $\boldsymbol{a}_{l}$ are the activity vectors of the gas and liquid species. For ionic components the elements of the activity vector $a_{i}=\gamma_{i} m_{i}$, where $\gamma_{i}$ and $m_{i}$ are the activity coefficient and molality (mol kg${ }^{-1}$ water), respectively, of component $i$. The water activity is denoted by $a_{w}$. Equations (1)-(5) represent a constrained nonlinear minimization problem.

Water exists in the atmosphere in an amount on the order of $\mathrm{g} \mathrm{m}^{-3}$ of air while in the aerosol phase at less than $1 \mathrm{mg} \mathrm{m}^{-3}$ of air. As a result, the transport of water to and from the aerosol phase does not affect the ambient partial pressure of water in the atmosphere, which is controlled by larger scale meteorological factors. Thus, by neglecting curvature, the equilibrium of water between the gas and aerosol phases is defined by $a_{w}=R H$, where $R H$ is the relative humidity in the atmosphere, expressed as a fraction. For a curved surface, i.e., that of sub-100 nm particles, the equilibrium partial pressure of a gas component $i$ is greater than that required for a flat surface as described by the Kelvin equation (Seinfeld and Pandis, 1998). Inclusion of curvature can be readily handled by an extension of the solution methods presented in the paper.

The key parameters in the equilibrium calculation are the activity coefficients. For aqueous inorganic electrolyte solutions, the Pitzer molality-based model (Pitzer, 1973, 1975; Pitzer and Mayorga, 1973) had been widely used, but it is restricted to high $R H$ regions where solute molalities are low. These concentration restrictions were relaxed with the Pitzer, Simonson, Clegg (PSC) mole fraction-based model (Clegg and Pitzer, 1992; Clegg et al., 1992). On a mole fraction scale, the activity of component $i$ is expressed as $a_{i}=f_{i} x_{i}$, where $f_{i}$ is the mole fraction-based activity coefficient, and $x_{i}$ is the mole fraction of species $i$. The molality- and mole fraction-based activity coefficients are related by $f_{i} x_{w}=\gamma_{i}$. A number of methods exist for calculating the water activity $a_{w}$. The most widely used is the ZSR mixing rule (Stokes and Robinson, 1966; Clegg et al., 2003), in which only data on binary solute/water solutions are needed to predict the water content of a multicomponent mixture. A more accurate determination of the water content can be obtained using the solvent activity model of Clegg et al. (1998a,b), which includes interactions between solutes, in addition to those between the solutes and water; in this case, the water activity is calculated from $a_{w}=f_{w} x_{w}$.

The numerical algorithm for thermodynamic equilibrium problems related to modeling of atmospheric inorganic aerosols has been implemented in UHAERO as module 1 (inorganic thermo) and incorporated together with two mole fraction based multicomponent activity coefficient models, namely the PSC model and the Extended UNIQUAC (ExUNIQUAC) model (Thomsen and Rasmussen, 1999). The temperature dependence of the standard state chemical potential is calculated from

$\mu_{i}^{0}(T)=T\left[\frac{\Delta G_{f}^{0}}{T_{0}}+\Delta H\left(\frac{1}{T}-\frac{1}{T_{0}}\right)+c_{p}\left(\ln \frac{1}{T}-\frac{T_{0}}{T}+1\right)\right]$

where $\Delta G_{f}^{0}$ is the free energy of formation, $\Delta H$ the standard heat of formation, and $c_{p}$ the heat capacity, of component $i$, all at $T_{0}$, a reference temperature. In conjunction with the 
PSC and ExUNIQUAC models, we use the data sets of tabulated values of $\Delta G_{f}^{0}, \Delta H$ and $c_{p}$ for the components in solid phases, as reported in Clegg et al. (1998a) and Thomsen and Rasmussen (1999), where one can find analysis of the sensitivity of computed deliquescence behavior to such data sets. It shall be noted that the inclusion of the ExUNIQUAC model in the present paper is to illustrate that the UHAERO framework is applicable to any number of components with any activity coefficient model. The UHAERO code has been prepared so that it may be easily used by the community. The PSC model has been incorporated in the Aerosol Inorganic Model (AIM). The AIM thermodynamic models are considered as the most comprehensive and accurate over the entire range of compositions and relative humidities. To assess the computational performance, UHAERO module 1 using PSC (UHAERO-PSC) will be benchmarked against predictions obtained with AIM. The phase state and chemical composition of ammonium/sulfate/nitrate aerosols at thermodynamic equilibrium will be investigated via the reconstruction of comprehensive phase-diagrams. UHAERO-PSC can be run in two modes: (1) the water content in the system is specified; (2) the system is equilibrated to a fixed relative humidity $(R H)$. In case (2), the aerosol water content is directly computed from the minimization process, i.e., without using an empirical relationship such as the ZSR equation. The water activity is predicted using PSC in both cases. Also, in both cases, the equilibration of trace gases between the vapor and condensed phases can be enabled or disabled as required, as can the formation of solids, which allows the properties of liquid aerosols supersaturated with respect to solid phases to be investigated.

Traditional optimization algorithms applied (in Table 1) for the prediction of inorganic gas-aerosol equilibrium are often related to sequential quadratic programming methods for nonlinear programming, often combined with interiorpoint techniques for the handling of the non-negativity constraints on the concentrations of salts. One major difference that arises when nonlinear programming algorithms are applied as "black boxes" to solve gas-aerosol equilibrium problems is that the former typically employs generic linear algebra routines to solve linear systems arising in the algorithm, whereas for gas-aerosol equilibrium problems, specific sparse direct linear solvers that explore the special algebraic structure of gas-liquid and liquid-solid equilibrium relations have to be used in order to deal with the poor scaling of the concentrations in the computation. It is known that a straight forward application of nonlinear programming algorithms is not effective, and that instead the iterates should be computed based on a primal-dual active set method. The numerical minimization technique of UHAERO is based on a primal-dual active-set algorithm, which is described in detail elsewhere (Amundson et al., 2005, 2006). The algorithm is elucidated from the analysis of the algebraic structure of the Karush-Kuhn-Tucker (KKT) optimality conditions for the minimization of the Gibbs free energy. The reformulated
KKT system is first derived to furnish the mass action laws in addition to the mass balance constraints (2). The mass action laws are in a logarithmic form. An immediate consequence of the logarithmic form is that the mass action laws in the primal-dual form are linear with respect to the dual variables, which represent the logarithmic values of activities for component species at equilibrium. In this primal-dual form, the mass action laws involving solid phases become linear inequality constraints that are enforced via the dual variables so that the solution remains dual feasible with respect to salt saturations. The concentrations of saturated salts are the Lagrange multipliers of the dual linear constraints that are active, thus can be eliminated from the KKT system by applying the so-called null-space method based on an active set of solid phases. Then, the algorithm applies Newton's method to the reduced KKT system of equations that is projected on the active set of solid phases to find the next primal-dual approximation of the solution. The active set method adds a solid salt when the components reach saturation and deletes a solid phase from the active set when its concentration violates the non-negativity constraint. The analysis of linear algebra with matrices of block structure provides information about the inertia of the so-called KKT matrices which arise in the Newton iterations. This information is used, as phase stability criteria, in line-search based methods to detect negative curvature and modify, if necessary, the second order information to ensure that the algorithm converges to a stable equilibrium rather than to any other first-order optimality point, such as a maximum, a saddle point, or an unstable local minimum. The iterates of concentrations follow a path that is infeasible with respect to the mass balance constraints in the first few iterations, then converge quadratically to the minimum of the Gibbs free energy.

\section{Computation of the crystallization of metastable solu- tions}

Transformation from a metastable phase, such as a supersaturated aqueous solution, to a thermodynamically more favorable phase, such as a crystal salt, is initiated by the nucleation and growth of a germ of the new phase. It is reasonable to assume that the overall time over which crystallization occurs is controlled by the time required for nucleation of a single germ, and that the subsequent crystal growth is rapid. The energy required for the formation of a germ of volume $V_{\text {germ }}$ and surface area $A_{\text {germ }}$ is the difference in the energy cost of creating the two-dimensional interface with the surrounding aqueous medium and the energy released from the three-dimensional association of the germ:

$\Delta G_{\text {germ }}=-\Delta \mu_{s} \rho_{\text {germ }}^{0} V_{\text {germ }}+\sigma_{\text {germ }} A_{\text {germ }}$.

where $\rho_{\text {germ }}^{0}$ is the molecular density of the germ and $\sigma_{\text {germ }}$ is its surface tension. The free energy barrier $\Delta G_{\text {crit }}$ that must 
be surmounted to form a nucleus of critical size is that at the maximum of $\Delta G_{\text {germ }}$; we have

$$
\Delta G_{\text {crit }}=\frac{16 \pi}{3} c_{\text {geom }} \frac{\sigma_{\text {germ }}^{3}}{\left(\rho_{\text {germ }}^{0} R T \ln S\right)^{2}},
$$

where $S(>1)$ is the saturation ratio of the aqueous phase, which is supersaturated with respect to the salt that forms a nucleus. Thus, $\Delta G_{\text {crit }}$ is the energy required for the formation of a critical nucleus for which the energy released from its formation exceeds the energy cost of creating the interface with the medium. It shall be noted that Eq. (7) models only homogeneous nucleation, and can be extended straightforwardly to treat heterogeneous nucleation via the relation $\Delta G_{\text {crit }}^{\text {hete }}=\Delta G_{\text {crit }} \psi(\theta)$, where $\psi(\theta)$ describes the efficacy of the heterogeneous nucleus in terms of $\theta$, the contact angle formed between the germ and the substrate. However, the mire of details in modeling $\psi(\theta)$ according to classical heterogeneous nucleation theory is often difficult. Thus, we limit the scope of the theory in the present paper to the treatment of homogeneous nucleation. In Eq. (7), the constant factor $c_{\text {geom }}$ is a geometrical parameter defined as

$c_{\text {geom }}=\frac{1}{36 \pi} \frac{A_{\text {germ }}^{3}}{V_{\text {germ }}^{2}}$.

In general, $c_{\text {geom }} \geq 1$, where $c_{\text {geom }}=1$ holds for a spherical nucleus. For a cubic nucleus, $c_{\text {geom }} \geq \frac{6}{\pi} \approx 1.909$. When the classical nucleation theory is used, the thermodynamic properties of the nucleus are assumed to be those of the bulk substance in question. For most salts of interest here, $c_{\text {geom }} \approx 2$. In the present calculation, we employ the

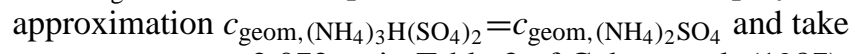

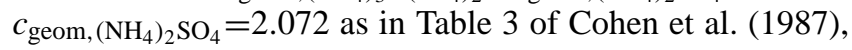
where the value of $c_{\text {geom }}$ for $\left(\mathrm{NH}_{4}\right)_{2} \mathrm{SO}_{4}$ as 2.072 was obtained by assuming shape based upon bulk crystallography. The molecular density of the germ $\rho_{\text {germ }}^{0}$ can be obtained via $\rho_{\text {germ }}^{0}:=\frac{1}{v_{\text {germ }}^{0}}$, where $v_{\text {germ }}^{0}$ is the molecular volume. Here we take $v_{\text {germ }}^{0}=85.307$ for $\left(\mathrm{NH}_{4}\right)_{2} \mathrm{SO}_{4}$ and 148.99 for $\left(\mathrm{NH}_{4}\right)_{3} \mathrm{H}\left(\mathrm{SO}_{4}\right)_{2}$ as in Tang and Munkelwitz (1994).

According to classical nucleation theory, the nucleation rate $J_{\text {nucl }}\left(\mathrm{cm}^{-3} \mathrm{~s}^{-1}\right)$, describing the number of nuclei (i.e., a critical germ) formed per volume per time, is given by:

$J_{\text {nucl }}=J_{0} \exp \left(\frac{-\Delta G_{\text {crit }}}{k T}\right)$,

where $k$ is the Boltzmann constant, and $J_{0}\left(\mathrm{~cm}^{-3} \mathrm{~s}^{-1}\right)$ is a pre-exponential factor that is related to the efficiency with which collisions between supernatant ions and the crystal interface produce crystal growth. $J_{0}$ usually is approximated by $J_{0} \approx N \frac{k T}{h}$, where $N$ is the molecular concentration in the liquid phase and $h$ is Planck's constant. $J_{0}$ has a value of order $10^{24}-10^{36}$. The results do not depend strongly on the pre-exponential factor and we follow Cohen et al. (1987) and choose $J_{0}=10^{30}$. For salt nucleation from an aqueous supersaturated droplet, the nucleation rate $J_{\text {nucl }}$ depends on the mole fraction composition of the aqueous particle and, consequently, ambient relative humidity when water activity is maintained in equilibrium with the gas-phase. Nucleation is a stochastic process, that can be approximated by the Poisson distribution. After a time, $t$, the probability of an individual particle having produced a critical nucleus is given by $P_{\text {nucl }}(t)=1-\exp \left(-J_{\text {nucl }} V_{p} t\right)$, where $V_{p}\left(\mathrm{~cm}^{3}\right)$ is the particle volume. This probability also describes complete crystallization when crystal growth is rapid compared to the nucleation time. The expectation time $\tau_{\text {nucl }}$ after which a particle of volume $V_{p}$ forms a single nucleus is given by

$\tau_{\text {nucl }}=\frac{1}{J_{\text {nucl }} V_{p}}$.

In order to apply the classical nucleation theory (CNT) in the computation of crystallization of salts on the metastable branch of the hysteresis curve, one needs surface tension data for the supersaturated aqueous salts solutions. Although a number of methods for calculating surface tension of dilute aqueous solutions of single electrolytes exist, there are few theoretical models available for the surface tension of aqueous solutions of highly concentrated and mixed electrolytes (Chen, 1994; Li et al., 1999; Li and Lu, 2001; Hu and Lee, 2004). Topping et al. (2005) present a summary of models for the surface tension of aqueous electrolyte solutions. We first calculate the surface tensions for the single-electrolyte aqueous solutions, $\mathrm{H}_{2} \mathrm{SO}_{4}$ and $\left(\mathrm{NH}_{4}\right)_{2} \mathrm{SO}_{4}$, respectively, to correlate model parameters against the laboratory data reported in Martin et al. (2000) for $\mathrm{H}_{2} \mathrm{SO}_{4} / \mathrm{H}_{2} \mathrm{O}$ and $\mathrm{HNO}_{3} / \mathrm{H}_{2} \mathrm{O}$ and in Korhonen et al. (1998) for $\left(\mathrm{NH}_{4}\right)_{2} \mathrm{SO}_{4} / \mathrm{H}_{2} \mathrm{O}$. No data are available for $\mathrm{NH}_{4} \mathrm{NO}_{3} / \mathrm{H}_{2} \mathrm{O}$. We employ $\mathrm{Li}$ and Lu's (Li and Lu, 2001) formula for the surface tension of single electrolyte aqueous solutions,

$\sigma=\sigma_{w}-R T \Gamma_{\mathrm{MX}}^{w_{0}} \ln \left(1+K_{\mathrm{MX}} a_{\mathrm{MX}}\right)$,

where $\sigma_{w}$ is the pure water surface tension at the system temperature and $a_{\mathrm{MX}}$ is the activity of the electrolyte MX. The two parameters of Eq. (11), $\Gamma_{\mathrm{MX}}^{w_{0}}$ and $K_{\mathrm{MX}}$ are obtained from correlating the surface tension $\sigma$ against the measurements of Martin et al. (2000) and Korhonen et al. (1998) for $\mathrm{MX}=\mathrm{H}_{2} \mathrm{SO}_{4}$ and $\mathrm{MX}=\left(\mathrm{NH}_{4}\right)_{2} \mathrm{SO}_{4}$, respectively. Without introducing any additional parameters or empirical coefficients, the fitted parameters are capable of predicting surface tensions of mixed-electrolyte aqueous solutions. The calculation is based on the formula for the surface tension of mixed electrolyte aqueous solutions ( $\mathrm{Li}$ and $\mathrm{Lu}, 2001$ ),

$\sigma=\sigma_{w}-R T \sum_{i=1}^{n} \Gamma_{i}^{w_{0}} \ln \left(1+K_{i} a_{i}\right)$,

where, for the binary system $\left(\mathrm{NH}_{4}\right)_{2} \mathrm{SO}_{4} / \mathrm{H}_{2} \mathrm{SO}_{4}$, we have $n=2, i \in\{1,2\}=\left\{\left(\mathrm{NH}_{4}\right)_{2} \mathrm{SO}_{4}, \mathrm{H}_{2} \mathrm{SO}_{4}\right\}$, and $\Gamma_{i}^{w_{0}}$ and $K_{i}$ 
are determined from Eq. (11). Note that, for the predicted surface tension of this binary aqueous electrolyte system, the acid and its salt have opposite effects on surface tension as their concentrations increase.

We employ Antonoff's rule to obtain the surface tension of crystalline germs in aqueous electrolyte solutions, $\sigma_{\text {germ }}$ (i.e., between the crystal and the liquid), as the absolute value of the difference between $\sigma_{\text {crystal/air }}$ and $\sigma_{\text {liquid/air }}$; that is

$\sigma_{\text {germ }}:=\sigma_{\text {crystal } / \text { liquid }}=\left|\sigma_{\text {crystal } / \text { air }}-\sigma_{\text {liquid/air }}\right|$.

In Eq. (13), the surface tension of aqueous electrolyte solutions $\sigma_{\text {liquid/air }}$ can be obtained from Eq. (12), whereas $\sigma_{\text {crystal/air }}$ is assumed to be a constant for a given crystal and is to be determined as a parameter based on one value of $\sigma_{\text {germ }}$, which, in turn, can be computed from one measurement of the efflorescence $R H$ of the corresponding crystalline salt. Cohen et al. (1987) correlated, based on classical nucleation theory, the value for the surface tension of salt $\left(\mathrm{NH}_{4}\right)_{2} \mathrm{SO}_{4}$ in the solute mixture of $\mathrm{ASR}=2$ (ASR: ammonium-sulfate-ratio) with measured efflorescence $R H$. The computed value $\sigma_{\left(\mathrm{NH}_{4}\right)_{2} \mathrm{SO}_{4}}(\mathrm{ASR}=2)=0.0368 \mathrm{~kg} \mathrm{~s}^{-2}$, reported in Cohen et al. (1987), is used to determine the parameter $\sigma_{\text {crystal/air }}$ in Eq. (13) for the calculation of the surface tension of crystalline germs of $\left(\mathrm{NH}_{4}\right)_{2} \mathrm{SO}_{4}$ in aqueous electrolyte solutions of $0<\mathrm{ASR}<2$. Since there are apparently no data reported in the literature for the surface tension of the salt $\left(\mathrm{NH}_{4}\right)_{3} \mathrm{H}\left(\mathrm{SO}_{4}\right)_{2}$, the parameter $\sigma_{\text {crystal/air }}$ in Eq. (13) for $\left(\mathrm{NH}_{4}\right)_{3} \mathrm{H}\left(\mathrm{SO}_{4}\right)_{2}$ is computed from the measured efflorescence $R H$ of the corresponding crystalline salt in the solute mixture of ASR=1.5, reported by Martin et al. (2003). More precisely, the surface tension of crystalline germs $\left(\mathrm{NH}_{4}\right)_{3} \mathrm{H}\left(\mathrm{SO}_{4}\right)_{2}$ in aqueous electrolyte solutions of $0<\mathrm{ASR}<2$ is determined by adjusting the parameter $\sigma_{\text {crystal/air }}$ in Eq. (13) so that the computed efflorescence $R H$ at ASR=1.5 matches the lower bound of the measured efflorescence $R H=22 \%$.

The major advantage of classical nucleation theory is that the expectation time of the crystallization of metastable solutions is conveniently related to the thermodynamic properties of the nucleus such as the shape $c_{\text {geom }}$, molecular volume $v_{\text {germ }}^{0}$ and surface tension $\sigma_{\text {germ }}$. However, major conceptual shortcomings also exist in assuming bulk values of $c_{\text {geom }}$, $v_{\text {germ }}^{0}$ and $\sigma_{\text {germ }}$ are relevant at the cluster level, where the nucleus consists of a statistically small number of molecules. In fact, we consider here classical nucleation theory as a semiempirical correlation, and we calibrate the values of $c_{\text {geom }}$, $v_{\text {germ }}^{0}$ and $\sigma_{\text {crystal/air }}$, as parameters for the calculation of the crystallization time $\tau_{\text {nucl }}$ in Eq. (10), so that the computed efflorescence $R H$ matches the measured value. Any extrapolations beyond the domain of calibration needs be done with caution. The application of classical nucleation theory to predict efflorescence has yet to be rigorously tested and the current model combined with measurements such as the data reported in Schlenker et al. (2004) provides an opportunity to do so.
The active-set numerical solution strategy described above has been extended to the computation of crystallization, the details of which are given elsewhere. In short, the supersaturated aqueous salts that are expected to crystallize in a given time interval are converted into crystalline components. Then the matrix algebra is updated to reflect the new set of crystal components, and the minimization problem is solved by Newton iteration.

\section{Simulation of inorganic phase equilibria and deli- quescence/crystallization}

The inorganic system that is arguably the most important with respect to atmospheric gas-aerosol equilibrium and aerosol state is that of sulfate, nitrate, ammonium, and water. Particles consisting of such species can be fully aqueous, fully crystalline, or consist of liquid-solid mixtures, depending on the relative concentrations of the components, $R H$, and temperature (Martin, 2000). In the present work we focus on this system and present results of application of UHAERO to the computation of its phase diagrams.

To reconstruct phase diagrams of the five-component system $\mathrm{SO}_{4}^{2-} / \mathrm{NO}_{3}^{-} / \mathrm{NH}_{4}^{+} / \mathrm{H}^{+} / \mathrm{H}_{2} \mathrm{O}$, we use the $X$ and $Y$ composition coordinates introduced by Potukuchi and Wexler (1995) and define:

$$
\begin{aligned}
& X=\text { Ammonium Fraction }=\frac{b_{\mathrm{NH}_{4}^{+}}}{b_{\mathrm{NH}_{4}^{+}}+b_{\mathrm{H}^{+}}}, \\
& Y=\text { Sulfate Fraction }=\frac{b_{\mathrm{SO}_{4}^{2-}}}{b_{\mathrm{SO}_{4}^{2-}}+b_{\mathrm{NO}_{3}^{-}}},
\end{aligned}
$$

where the system feeds $b_{\mathrm{SO}_{4}^{2-}}, b_{\mathrm{NO}_{3}^{-}}, b_{\mathrm{NH}_{4}^{+}}$, and $b_{\mathrm{H}^{+}}$are subject to electro-neutrality. It is more convenient to use the feeds in term of $\left(\mathrm{NH}_{4}\right)_{2} \mathrm{SO}_{4} / \mathrm{H}_{2} \mathrm{SO}_{4} / \mathrm{NH}_{4} \mathrm{NO}_{3} / \mathrm{HNO}_{3} / \mathrm{H}_{2} \mathrm{O}$ and re-define the $X$ and $Y$ coordinates:

$$
\begin{aligned}
X & =\frac{2 b_{\left(\mathrm{NH}_{4}\right)_{2} \mathrm{SO}_{4}}+b_{\mathrm{NH}_{4} \mathrm{NO}_{3}}}{2 b_{\left(\mathrm{NH}_{4}\right)_{2} \mathrm{SO}_{4}}+2 b_{\mathrm{H}_{2} \mathrm{SO}_{4}}+b_{\mathrm{NH}_{4} \mathrm{NO}_{3}}+b_{\mathrm{HNO}_{3}}}, \\
Y & =\frac{b_{\left(\mathrm{NH}_{4}\right)_{2} \mathrm{SO}_{4}}+b_{\mathrm{H}_{2} \mathrm{SO}_{4}}}{b_{\left(\mathrm{NH}_{4}\right)_{2} \mathrm{SO}_{4}}+b_{\mathrm{H}_{2} \mathrm{SO}_{4}}+b_{\mathrm{NH}_{4} \mathrm{NO}_{3}}+b_{\mathrm{HNO}_{3}}} .
\end{aligned}
$$

Thus, for a fixed $(X, Y)$ coordinate, we can define a non-unique feed composition for the system $\quad\left(\mathrm{NH}_{4}\right)_{2} \mathrm{SO}_{4} / \mathrm{H}_{2} \mathrm{SO}_{4} / \mathrm{NH}_{4} \mathrm{NO}_{3} / \mathrm{HNO}_{3} / \mathrm{H}_{2} \mathrm{O}$ as $b_{\left(\mathrm{NH}_{4}\right)_{2} \mathrm{SO}_{4}}=\frac{1}{2} X, \quad b_{\mathrm{H}_{2} \mathrm{SO}_{4}}=\frac{Y}{1+Y}-\frac{1}{2} X, \quad b_{\mathrm{NH}_{4} \mathrm{NO}_{3}}=\frac{1-Y}{1+Y}$, $b_{\mathrm{HNO}_{3}}=0, \quad$ if $\quad X \leq \frac{Y}{1+Y} ; \quad$ otherwise, $\quad b_{\left(\mathrm{NH}_{4}\right)_{2} \mathrm{SO}_{4}}=\frac{Y}{1+Y}$, $b_{\mathrm{H}_{2} \mathrm{SO}_{4}}=0, b_{\mathrm{NH}_{4} \mathrm{NO}_{3}}=X-\frac{2 Y}{1+Y}, b_{\mathrm{HNO}_{3}}=1-X$.

For Case (1) where the water content of the system needs to be specified, we introduce an additional coordinate $Z$ that has values between 0 and 1 and define the water content $b_{\mathrm{H}_{2} \mathrm{O}}$ to be $b_{\mathrm{H}_{2} \mathrm{O}}=\frac{Y}{1+Y} \frac{Z}{1-Z}$. The coordinate $Z$ is actually a water fraction in the sense that it can be interpreted as

$$
Z=\frac{(1+Y) b_{\mathrm{H}_{2} \mathrm{O}}}{(1+Y) b_{\mathrm{H}_{2} \mathrm{O}}+b_{\mathrm{NH}_{4}^{+}}+b_{\mathrm{H}^{+}}} .
$$


To facilitate the computation of the boundaries in phase diagrams, we also introduce the fractions

$$
\begin{aligned}
& f_{\mathrm{NH}_{4}^{+}}=\frac{b_{\mathrm{NH}_{4}^{+}}}{b_{\mathrm{NH}_{4}^{+}}+b_{\mathrm{H}^{+}}+(1+Y) b_{\mathrm{H}_{2} \mathrm{O}}}, \\
& f_{\mathrm{H}^{+}}=\frac{b_{\mathrm{H}^{+}}}{b_{\mathrm{NH}_{4}^{+}}+b_{\mathrm{H}^{+}}+(1+Y) b_{\mathrm{H}_{2} \mathrm{O}}}, \\
& f_{\mathrm{H}_{2} \mathrm{O}}=1-\left(f_{\mathrm{NH}_{4}^{+}}+f_{\mathrm{H}^{+}}\right),
\end{aligned}
$$

which actually are the barycentric coordinates of the unit triangle with vertices $(1+Y) \mathrm{H}_{2} \mathrm{O}, \mathrm{NH}_{4}^{+}$and $\mathrm{H}^{+}$. For a fixed $Y$, the $(X, Z)$ coordinate is interchangeable with the fraction coordinate $\left(f_{\mathrm{NH}_{4}^{+}}, f_{\mathrm{H}^{+}}, f_{\mathrm{H}_{2} \mathrm{O}}\right)$ via $f_{\mathrm{NH}_{4}^{+}}=X(1-Z), f_{\mathrm{H}^{+}}=(1-X)(1-Z), f_{\mathrm{H}_{2} \mathrm{O}}=Z$, and, conversely, $X=\frac{f_{\mathrm{NH}_{4}^{+}}}{f_{\mathrm{NH}_{4}^{+}}+f_{\mathrm{H}^{+}}}, Z=1-\left(f_{\mathrm{NH}_{4}^{+}}+f_{\mathrm{H}^{+}}\right)$. Therefore, the two dimensional (2-D) phase diagrams for fixed $Y$ values can be generated in three coordinate systems: $(X, R H),(X, Z)$ and $\left(f_{\mathrm{H}^{+}}, f_{\mathrm{NH}_{4}^{+}}\right)$, which can be chosen on the basis of computational or graphic convenience.

Figure 1 shows the ammonium/sulfate/nitrate phase diagram at $298.15 \mathrm{~K}$ computed with UHAERO-PSC. Abscissa $X$ is the cation mole fraction arising from $\mathrm{NH}_{4}^{+}$, with the remainder coming from $\mathrm{H}^{+}$. This can be considered as the degree of neutralization of the particle. Ordinate $Y$ is the anion mole fraction arising from $\mathrm{SO}_{4}^{2-}$, with the balance being made up of $\mathrm{NO}^{3-}$. The four corners of Fig. 1 thus represent sulfuric acid (top left), ammonium sulfate (top right), ammonium nitrate (bottom right), and nitric acid (bottom left). Coordinate $Z$ is the third dimension, which is relative humidity. Figure 1 is identical to Fig. 1a of Martin et al. (2004), which was computed using the same activity coefficient model as that employed here. Seven possible solid phases exist in this system at $298.15 \mathrm{~K}$; these are labeled as A through $\mathrm{G}$. A denotes ammonium sulfate, $\left(\mathrm{NH}_{4}\right)_{2} \mathrm{SO}_{4}$ (AS); B denotes letovicite, $\left(\mathrm{NH}_{4}\right)_{3} \mathrm{H}\left(\mathrm{SO}_{4}\right)_{2}$ (LET); C denotes ammonium bisulfate, $\mathrm{NH}_{4} \mathrm{HSO}_{4}$ (AHS); D denotes ammonium nitrate, $\mathrm{NH}_{4} \mathrm{NO}_{3}(\mathrm{AN})$; $\mathrm{E}$ denotes the mixed salt, $2 \mathrm{NH}_{4} \mathrm{NO}_{3} \cdot\left(\mathrm{NH}_{4}\right)_{2} \mathrm{SO}_{4}(2 \mathrm{AN} \cdot \mathrm{AS}) ; \mathrm{F}$ denotes the mixed salt, $3 \mathrm{NH}_{4} \mathrm{NO}_{3} \cdot\left(\mathrm{NH}_{4}\right)_{2} \mathrm{SO}_{4}(3 \mathrm{AN} \cdot \mathrm{AS})$; and $\mathrm{G}$ denotes the mixed salt of ammonium nitrate and ammonium bisulfate, $\mathrm{NH}_{4} \mathrm{NO}_{3} \cdot \mathrm{NH}_{4} \mathrm{HSO}_{4}$ (AN.AHS). Regions outlined by heavy black lines show the first solid that reaches saturation with decreasing $R H$. The thin labeled solid lines are deliquescence relative humidity contours, and the dotted lines give the aqueous-phase $X-Y$ composition variation with decreasing relative humidity as more solid crystallizes. These so-called liquidus lines were introduced by Potukuchi and Wexler (1995).

Figures 2a, 4a, 6a, 8a and 10a show the computed phase diagrams in the $(X, R H)$ coordinate, with tracking of the presence of each phase, for the system $\left(\mathrm{NH}_{4}\right)_{2} \mathrm{SO}_{4} / \mathrm{H}_{2} \mathrm{SO}_{4} / \mathrm{NH}_{4} \mathrm{NO}_{3} / \mathrm{HNO}_{3} / \mathrm{H}_{2} \mathrm{O}$ at $298.15 \mathrm{~K}$ and fixed sulfate fraction $Y=1,0.85,0.5,0.3$ and 0.2 , re-

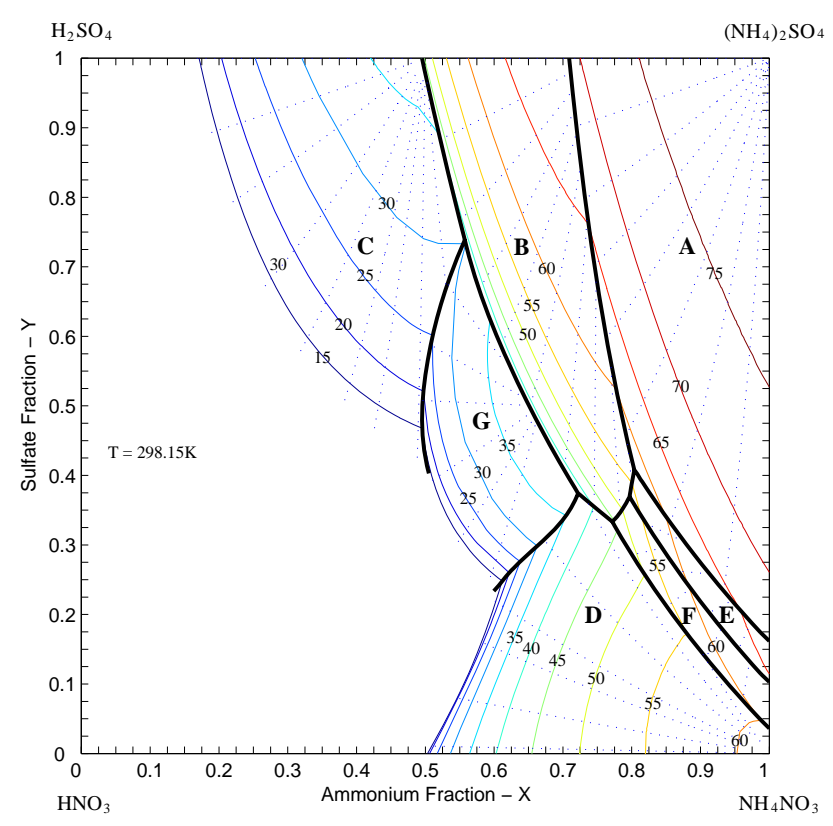

Fig. 1. Water activity contours at saturation (-) for the aqueous solution of $\mathrm{SO}_{4}^{2-} / \mathrm{NO}_{3}^{-} / \mathrm{NH}_{4}^{+} / \mathrm{H}^{+} / \mathrm{H}_{2} \mathrm{O}$ at $298.15 \mathrm{~K}$. The dotted lines $(\cdots)$ indicate the subsequent aqueous phase $(X, Y)$ composition with decreasing relative humidity as more solid crystallizes. Phase boundaries are marked with bold lines separating different solid phases. All the solid phases are identified and are marked. Labels on the contours present water activities at saturation which represent the deliquescence relative humidity values. This figure corresponds to the contour plot for Fig. 1 in Potukuchi and Wexler (1995) and Fig. 1a in Martin et al. (2004).

spectively. For each region of space whose boundaries are marked with bold lines, the existing phases at equilibrium are represented, where the liquid phase is labeled by L, and where, as in Fig. 1, the seven possible solid phases are labeled by A though G. Labels on the contours (-) present the aqueous phase $\mathrm{pH}$ values (defined as $\left.\mathrm{pH}=-\log _{10} a_{H^{+}}\right)$as a function of $X$ and $R H$. Accordingly, Figs. $2 b, 4 b, 6 b, 8 b$ and $10 b$ show relative particle mass contours (-) as a function of $X$ and $R H$ for the system $\left(\mathrm{NH}_{4}\right)_{2} \mathrm{SO}_{4} / \mathrm{H}_{2} \mathrm{SO}_{4} / \mathrm{NH}_{4} \mathrm{NO}_{3} / \mathrm{HNO}_{3} / \mathrm{H}_{2} \mathrm{O}$ at $298.15 \mathrm{~K}$ and fixed sulfate fraction $Y=1,0.85,0.5,0.3$ and 0.2 , respectively. The relative particle mass, also called particle mass growth factor, is defined as the ratio $\frac{W_{p}}{W_{\text {dry }}}$ of the particle mass $W_{p}$ at a specific $R H$ and $(X, Y)$ composition with respect to the particle mass $W_{\text {dry }}$ of the same $(X, Y)$ composition at the "dry-state". Since $W=W_{\text {dry }}+W_{\text {water, }}$, where $W_{\text {water }}$ is the water content in the particle system, by subtracting by 1 , the relative particle mass gives the relative water content $\frac{W_{\text {water }}}{W_{\text {dry }}}$ in the particle system.

To further demonstrate the capability for simulating the deliquescence behavior, Figs. 3, 5, 7, 9 

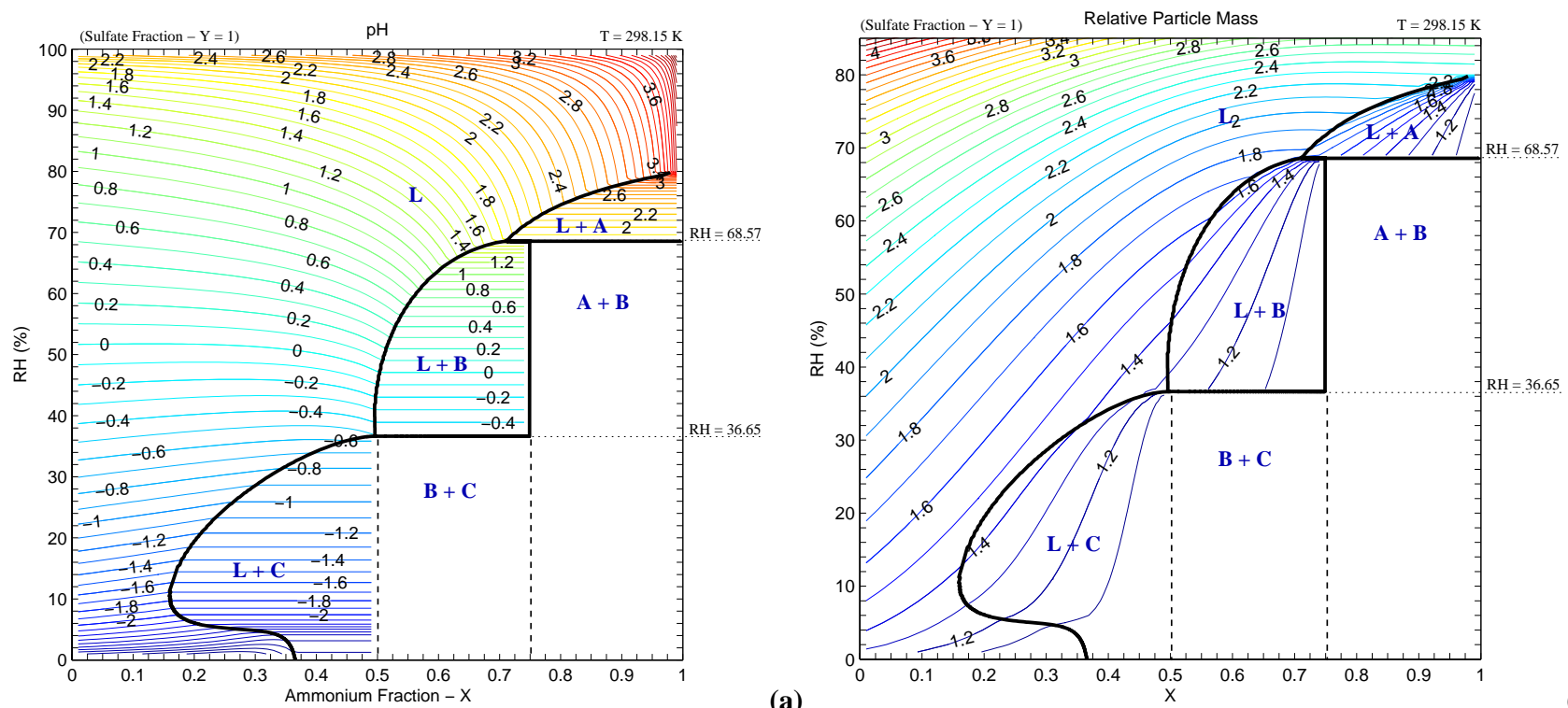

(b)

Fig. 2. Reconstruction of the phase diagram for the system $\left(\mathrm{NH}_{4}\right)_{2} \mathrm{SO}_{4} / \mathrm{H}_{2} \mathrm{SO}_{4} / \mathrm{H}_{2} \mathrm{O}$ at $298.15 \mathrm{~K}$ with tracking of the presence of each phase. For each region of space whose boundaries are marked with bold lines, the existing phases at equilibrium are represented. (a) Labels on the contours (-) present the aqueous phase $\mathrm{pH}$ values (equal to $-\log _{10} a_{H^{+}}$). (b) Labels on the contours (-) present the relative particle mass.
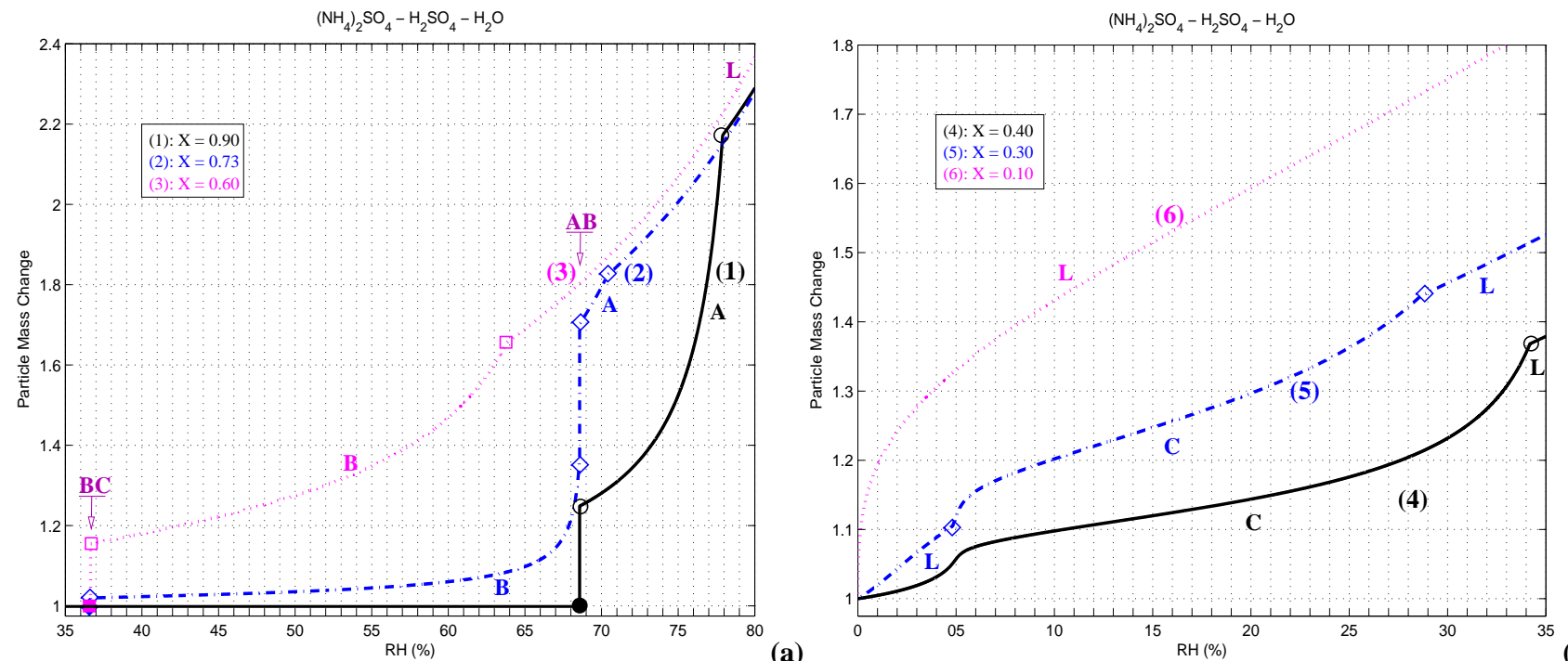

(b)

Fig. 3. Deliquescence curves for the system $\left(\mathrm{NH}_{4}\right)_{2} \mathrm{SO}_{4} / \mathrm{H}_{2} \mathrm{SO}_{4} / \mathrm{H}_{2} \mathrm{O}$ at $298.15 \mathrm{~K}$. Relative particle mass with changing relative humidity for several values of $X$. (a): (1) $X=0.9$, (2) $X=0.73$, (3) $X=0.6$. (b): (4) $X=0.4$, (5) $X=0.3$, (6) $X=0.1$. Curves (1) to (6) represent the relative particle mass on the vertical cuts at the corresponding $X$-values in Fig. 2 b.

and 11 show deliquescence curves for the system $\left(\mathrm{NH}_{4}\right)_{2} \mathrm{SO}_{4} / \mathrm{H}_{2} \mathrm{SO}_{4} / \mathrm{H}_{2} \mathrm{O}$ at $298.15 \mathrm{~K}$ for various $(X, Y)$ compositions. These figures correspond to the vertical cuts at the corresponding $X$-values in Figs. $2(Y=1), 4(Y=0.85)$, $6(Y=0.5), 8(Y=0.3)$, and $10(Y=0.2)$.
Figure 12 depicts the surface tension $\sigma_{\text {liquid/air }}$, computed based on Eq. (12), for the binary electrolyte aqueous solution $\left(\mathrm{NH}_{4}\right)_{2} \mathrm{SO}_{4} / \mathrm{H}_{2} \mathrm{SO}_{4} / \mathrm{H}_{2} \mathrm{O}$ at $298.15 \mathrm{~K}$. The activity coefficient calculation is carried out using the ExUNIQUAC model (Thomsen and Rasmussen, 1999). The parameters $\Gamma_{i}^{w_{0}}$ and $K_{i}, i \in\{1,2\}=\left\{\left(\mathrm{NH}_{4}\right)_{2} \mathrm{SO}_{4}, \mathrm{H}_{2} \mathrm{SO}_{4}\right\}$, in Eq. (12) 

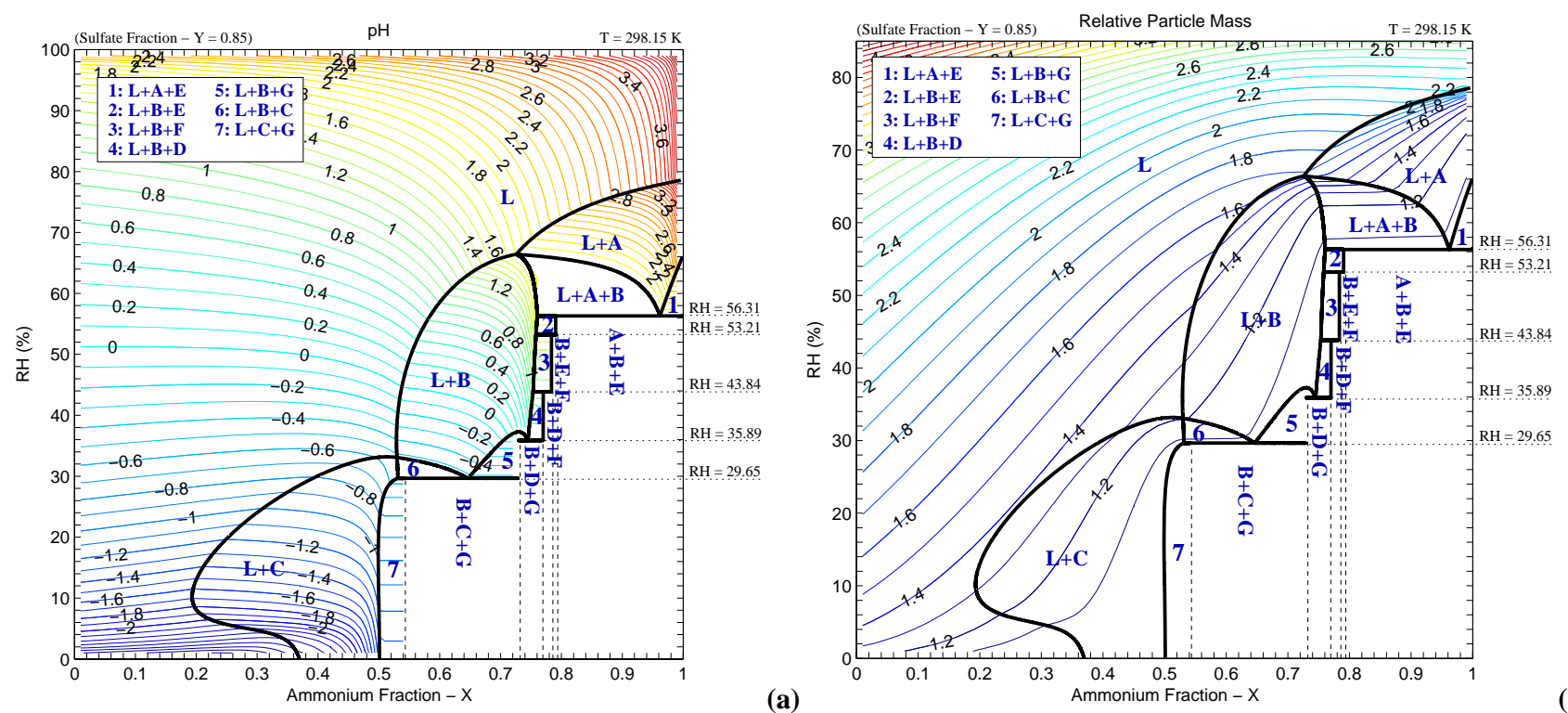

(b)

Fig. 4. Reconstruction of the phase diagram for the system $\left(\mathrm{NH}_{4}\right)_{2} \mathrm{SO}_{4} / \mathrm{H}_{2} \mathrm{SO}_{4} / \mathrm{NH}_{4} \mathrm{NO}_{3} / \mathrm{HNO}_{3} / \mathrm{H}_{2} \mathrm{O}$ with the sulfate fraction $Y=0.85$ at $298.15 \mathrm{~K}$ with tracking of the presence of each phase. For each region of space whose boundaries are marked with bold lines, the existing phases at equilibrium are represented. For the regions numbered as 1 through 7 , the existing phases at equilibrium are $\mathrm{L}+\mathrm{A}+\mathrm{E}, \mathrm{L}+\mathrm{B}+\mathrm{E}$, $\mathrm{L}+\mathrm{B}+\mathrm{F}, \mathrm{L}+\mathrm{B}+\mathrm{D}, \mathrm{L}+\mathrm{B}+\mathrm{G}, \mathrm{L}+\mathrm{B}+\mathrm{C}$, and $\mathrm{L}+\mathrm{C}+\mathrm{G}$, respectively. (a) Labels on the contours ( - ) present the aqueous phase $\mathrm{pH}$ values (equal to $-\log _{10} a_{H^{+}}$). (b) Labels on the contours (-) present the relative particle mass.
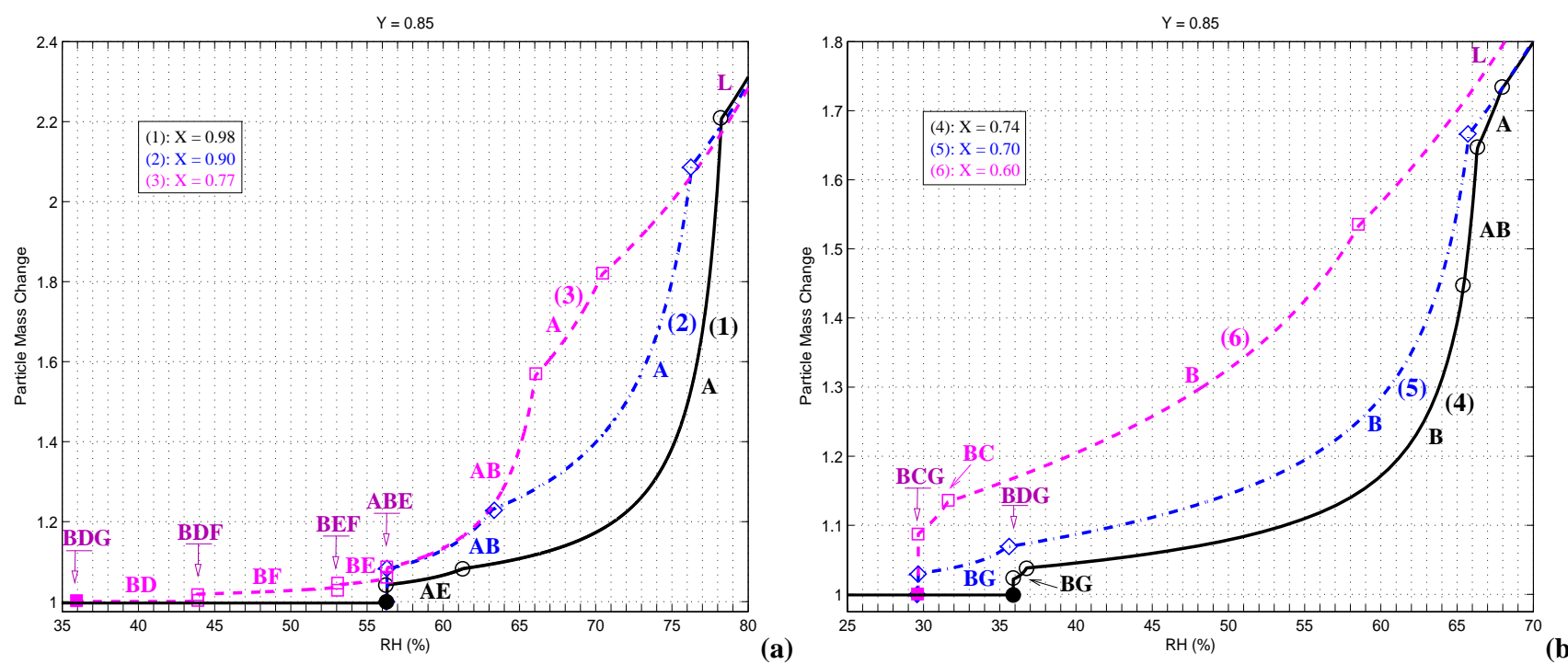

Fig. 5. Deliquescence curves for the system $\left(\mathrm{NH}_{4}\right)_{2} \mathrm{SO}_{4} / \mathrm{H}_{2} \mathrm{SO}_{4} / \mathrm{NH}_{4} \mathrm{NO}_{3} / \mathrm{HNO}_{3} / \mathrm{H}_{2} \mathrm{O}$ with the sulfate fraction $Y=0.85$ at $298.15 \mathrm{~K}$. Relative mass with changing relative humidity for several values of $X$. (a): (1) $X=0.98$, (2) $X=0.9$, (3) $X=0.77$. (b): (4) $X=0.74$, (5) $X=0.7$, (6) $X=0.6$. Curves (1) to (6) represent the relative particle mass on the vertical cuts at the corresponding $X$-values in Fig. $4 \mathrm{~b}$.

are determined from Eq. (11) by correlating the surface tension of the corresponding single electrolyte aqueous solutions against the measurements of Martin et al. (2000) and Korhonen et al. (1998). The original values of $\Gamma_{i}^{w_{0}}$ and $K_{i}$ as reported in $\mathrm{Li}$ and $\mathrm{Lu}(2001)$ are not suitable for the present calculation, as they were calibrated mostly with measurements of low concentrated electrolyte solutions and were obtained based on a different activity coefficient model. The accuracy of the surface tension calibration based on Li and Lu's formula, e.g., Eq. (12), depends largely on the applicability 

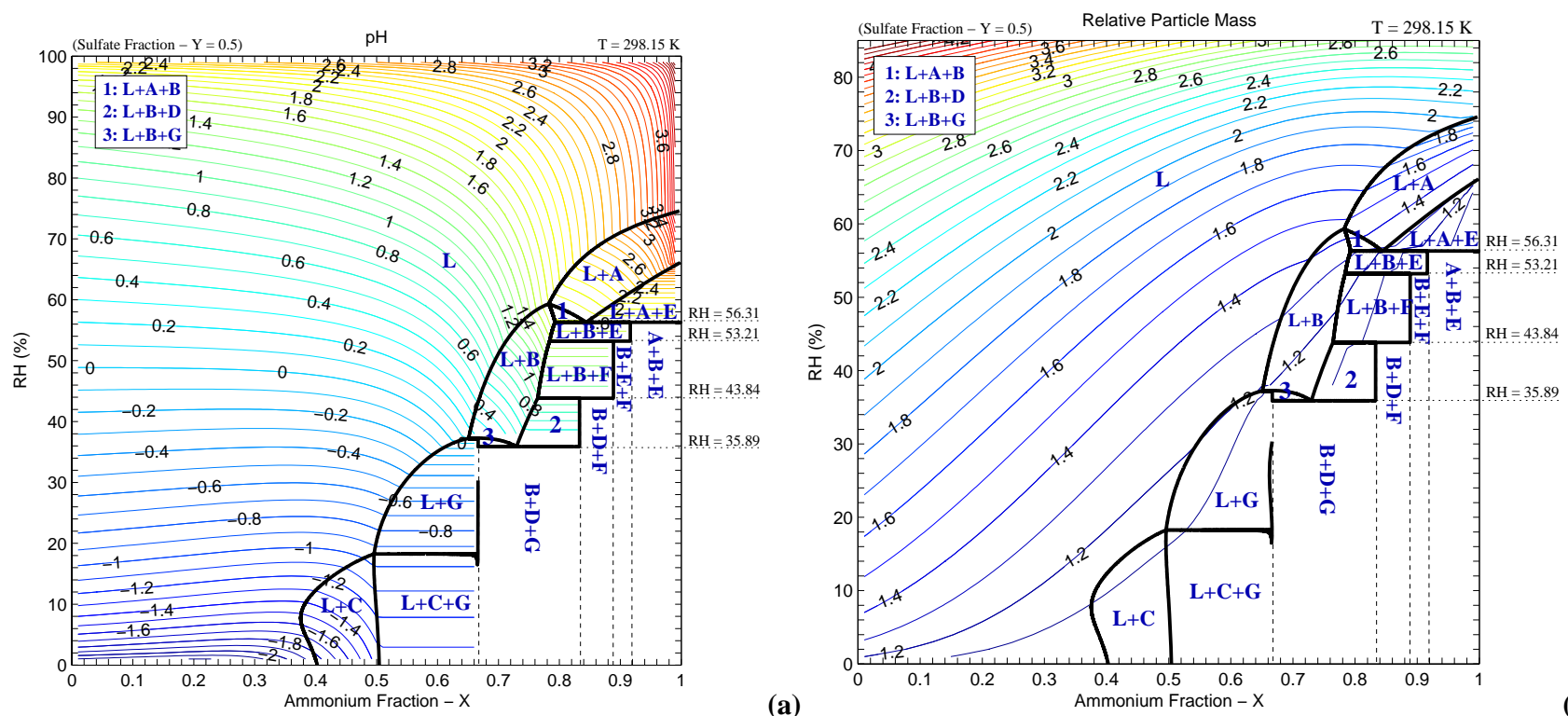

(b)

Fig. 6. Reconstruction of the phase diagram for the system $\left(\mathrm{NH}_{4}\right)_{2} \mathrm{SO}_{4} / \mathrm{H}_{2} \mathrm{SO}_{4} / \mathrm{NH}_{4} \mathrm{NO}_{3} / \mathrm{HNO}_{3} / \mathrm{H}_{2} \mathrm{O}$ with the sulfate fraction $Y=0.5$ at 298.15 K with tracking of the presence of each phase. For each region of space whose boundaries are marked with bold lines, the existing phases at equilibrium are represented. For the regions numbered as 1 through 3 , the existing phases at equilibrium are $\mathrm{L}+\mathrm{A}+\mathrm{B}, \mathrm{L}+\mathrm{B}+\mathrm{D}$, and $\mathrm{L}+\mathrm{B}+\mathrm{G}$, respectively. (a) Labels on the contours (-) present the aqueous phase pH values (equal to $-\log _{10} a_{H^{+}}$). (b) Labels on the contours (-) present the relative particle mass.
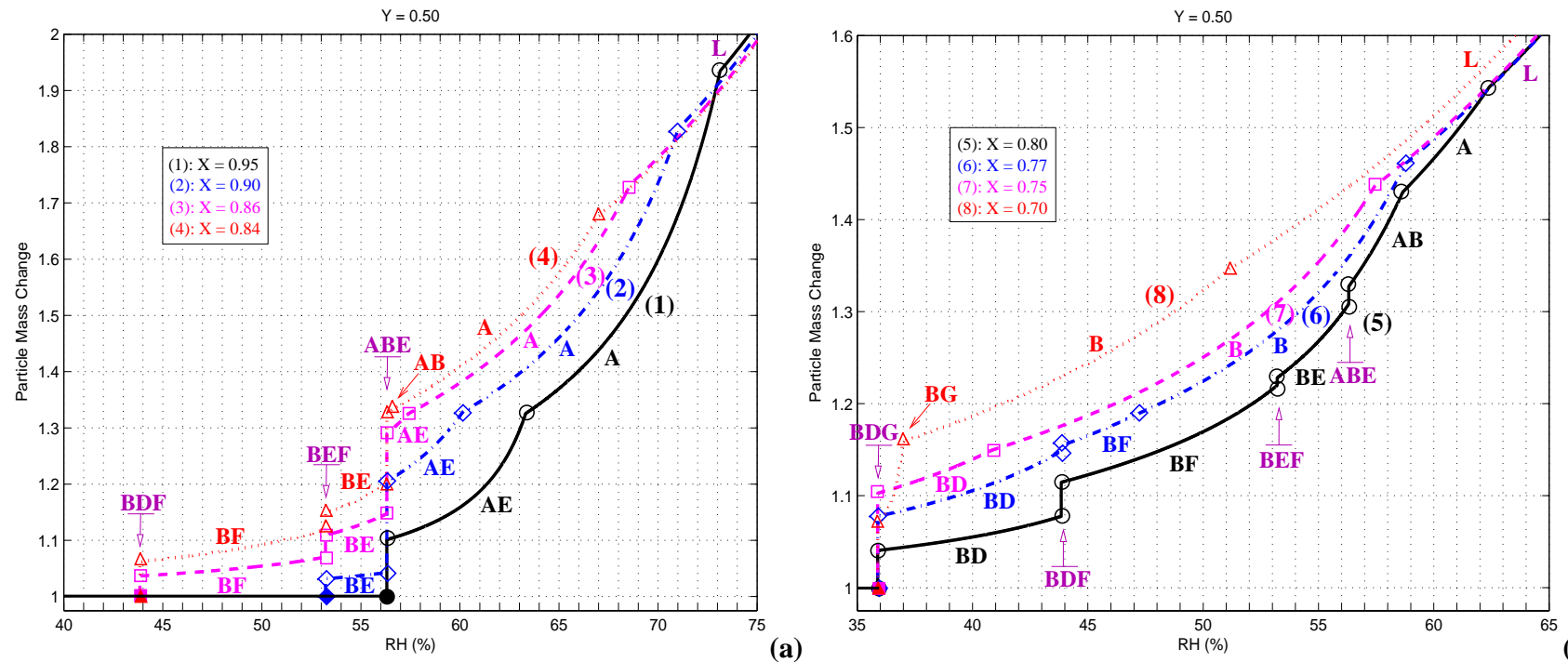

(b)

Fig. 7. Deliquescence curves for the system $\left(\mathrm{NH}_{4}\right)_{2} \mathrm{SO}_{4} / \mathrm{H}_{2} \mathrm{SO}_{4} / \mathrm{NH}_{4} \mathrm{NO}_{3} / \mathrm{HNO}_{3} / \mathrm{H}_{2} \mathrm{O}$ with the sulfate fraction $Y=0.5$ at $298.15 \mathrm{~K}$. Relative mass with changing relative humidity for several values of $X$. (a): (1) $X=0.95$, (2) $X=0.9$, (3) $X=0.86$, (4) $X=0.84$. (b): (5) $X=0.8$, (6) $X=0.77$, (7) $X=0.75$, (8) $X=0.7$. Curves (1) to (8) represent the relative particle mass on the vertical cuts at the corresponding $X$-values in Fig. 6b.

of activity coefficient models to supersaturated aqueous solutions of highly concentrated and mixed electrolytes. Most of the models that predict the activity coefficients of multicomponent aqueous solutions are empirical, or semi-empirical, and typically calibrated with activity measurements for multicomponent systems that are mostly available for relatively low ionic activities. As such, any application of current activity coefficient models to supersaturated aqueous solutions of 

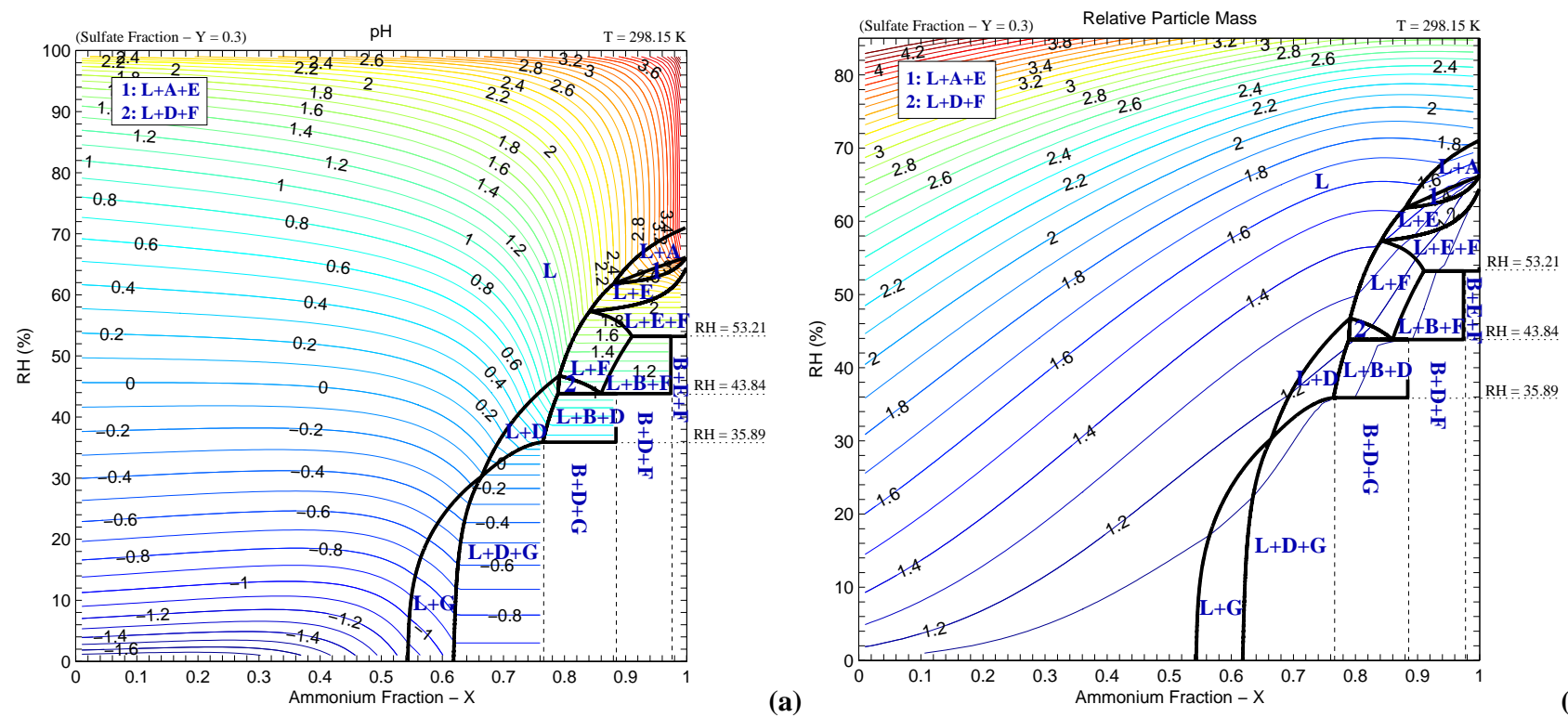

(b)

Fig. 8. Reconstruction of the phase diagram for the system $\left(\mathrm{NH}_{4}\right)_{2} \mathrm{SO}_{4} / \mathrm{H}_{2} \mathrm{SO}_{4} / \mathrm{NH}_{4} \mathrm{NO}_{3} / \mathrm{HNO}_{3} / \mathrm{H}_{2} \mathrm{O}$ with the sulfate fraction $Y=0.3$ at $298.15 \mathrm{~K}$ with tracking of the presence of each phase. For each region of space whose boundaries are marked with bold lines, the existing phases at equilibrium are represented. For the regions numbered as 1 and 2, the existing phases at equilibrium are $\mathrm{L}+\mathrm{A}+\mathrm{E}$ and $\mathrm{L}+\mathrm{D}+\mathrm{F}$, respectively. (a) Labels on the contours (-) present the aqueous phase $\mathrm{pH}$ values (equal to $-\log _{10} a_{H^{+}}$). (b) Labels on the contours (一) present the relative particle mass.
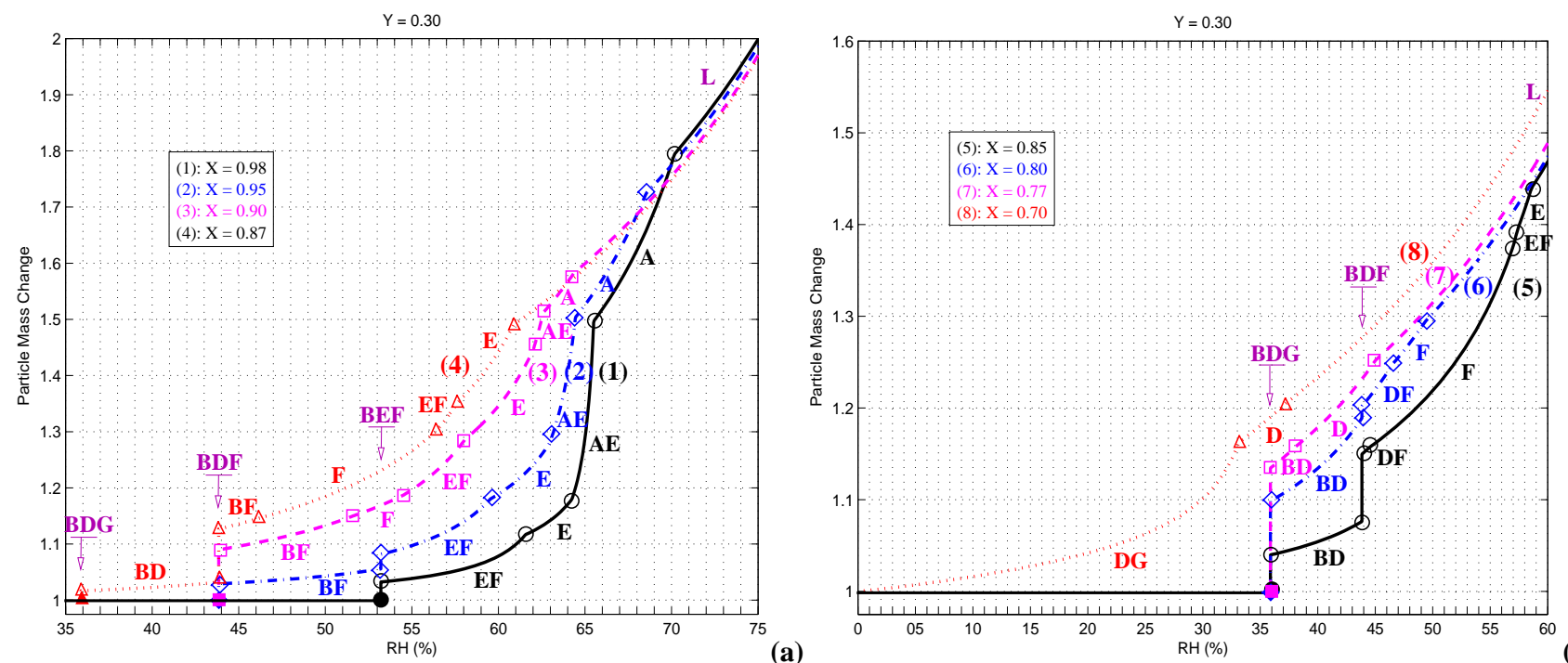

Fig. 9. Deliquescence curves for the system $\left(\mathrm{NH}_{4}\right)_{2} \mathrm{SO}_{4} / \mathrm{H}_{2} \mathrm{SO}_{4} / \mathrm{NH}_{4} \mathrm{NO}_{3} / \mathrm{HNO}_{3} / \mathrm{H}_{2} \mathrm{O}$ with the sulfate fraction $Y=0.3$ at $298.15 \mathrm{~K}$. Relative mass with changing relative humidity for several values of $X$. (a): (1) $X=0.98$, (2) $X=0.95$, (3) $X=0.9$, (4) $X=0.87$. (b): (5) $X=0.85$, (6) $X=0.8$, (7) $X=0.77$, (8) $X=0.7$. Curves (1) to (8) represent the relative particle mass on the vertical cuts at the corresponding $X$-values in Fig. 8b.

highly concentrated and mixed electrolytes is an extrapolation beyond the domain of calibration, thus should be viewed with caution. In fact, as one specific example of such extrapolation, we were unable to calibrate model parameters in Eq. (12) to obtain a satisfactory calculation of the surface tension $\sigma_{\text {liquid/air }}$ for the ternary electrolyte aqueous solution $\left(\mathrm{NH}_{4}\right)_{2} \mathrm{SO}_{4} / \mathrm{H}_{2} \mathrm{SO}_{4} / \mathrm{NH}_{4} \mathrm{NO}_{3} / \mathrm{HNO}_{3} / \mathrm{H}_{2} \mathrm{O}$; high deviations of the computed values of surface tension from the 

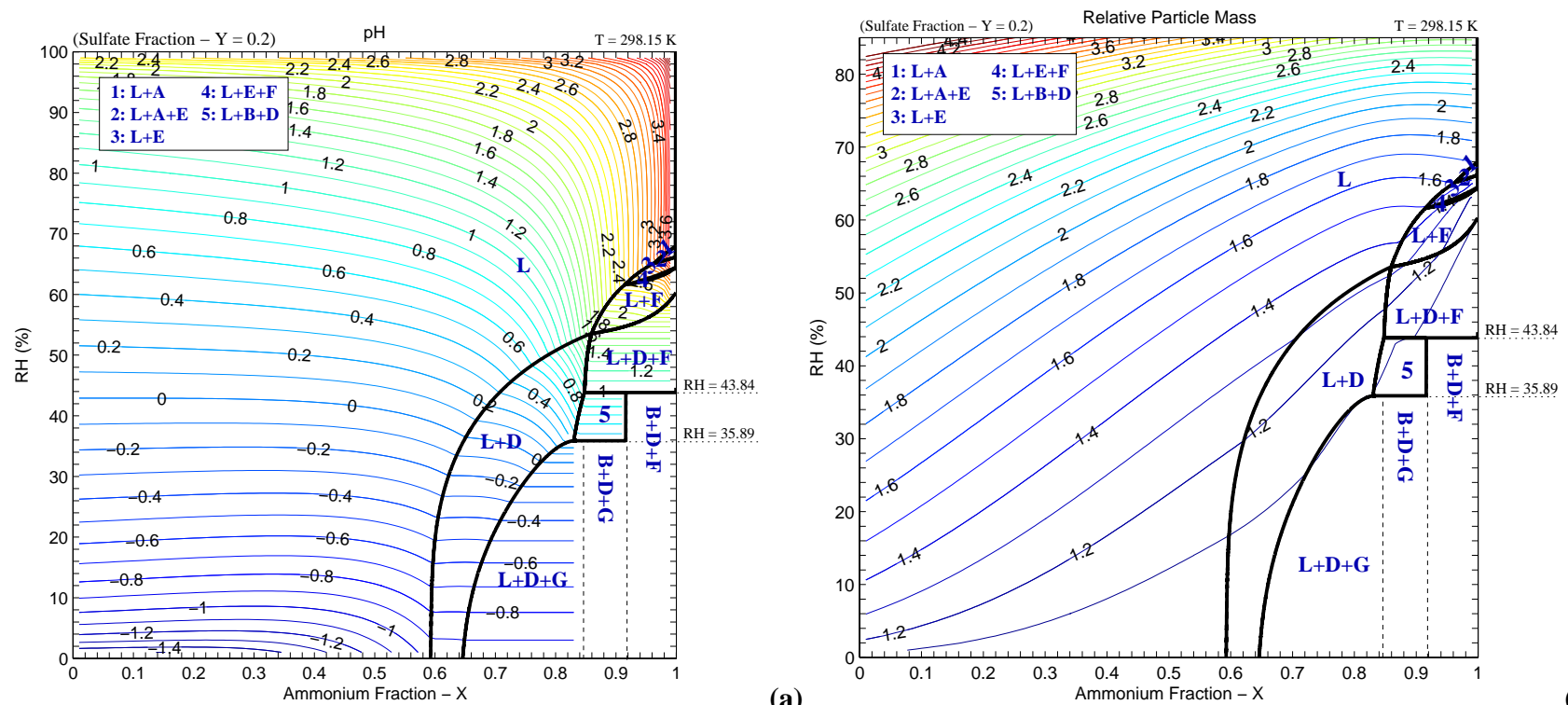

(a)

(b)

Fig. 10. Reconstruction of the phase diagram for the system $\left(\mathrm{NH}_{4}\right)_{2} \mathrm{SO}_{4} / \mathrm{H}_{2} \mathrm{SO}_{4} / \mathrm{NH}_{4} \mathrm{NO}_{3} / \mathrm{HNO}_{3} / \mathrm{H}_{2} \mathrm{O}$ with the sulfate fraction $Y=0.2$ at $298.15 \mathrm{~K}$ with tracking of the presence of each phase. For each region of space whose boundaries are marked with bold lines, the existing phases at equilibrium are represented. For the regions numbered as 1 through 5 , the existing phases at equilibrium are $\mathrm{L}+\mathrm{A}, \mathrm{L}+\mathrm{A}+\mathrm{E}, \mathrm{L}+\mathrm{E}$, $\mathrm{L}+\mathrm{E}+\mathrm{F}$, and $\mathrm{L}+\mathrm{B}+\mathrm{D}$, respectively. (a) Labels on the contours (-) present the aqueous phase pH values (equal to $\left.-\log _{10} a_{H^{+}}\right)$. (b) Labels on the contours (-) present the relative particle mass.
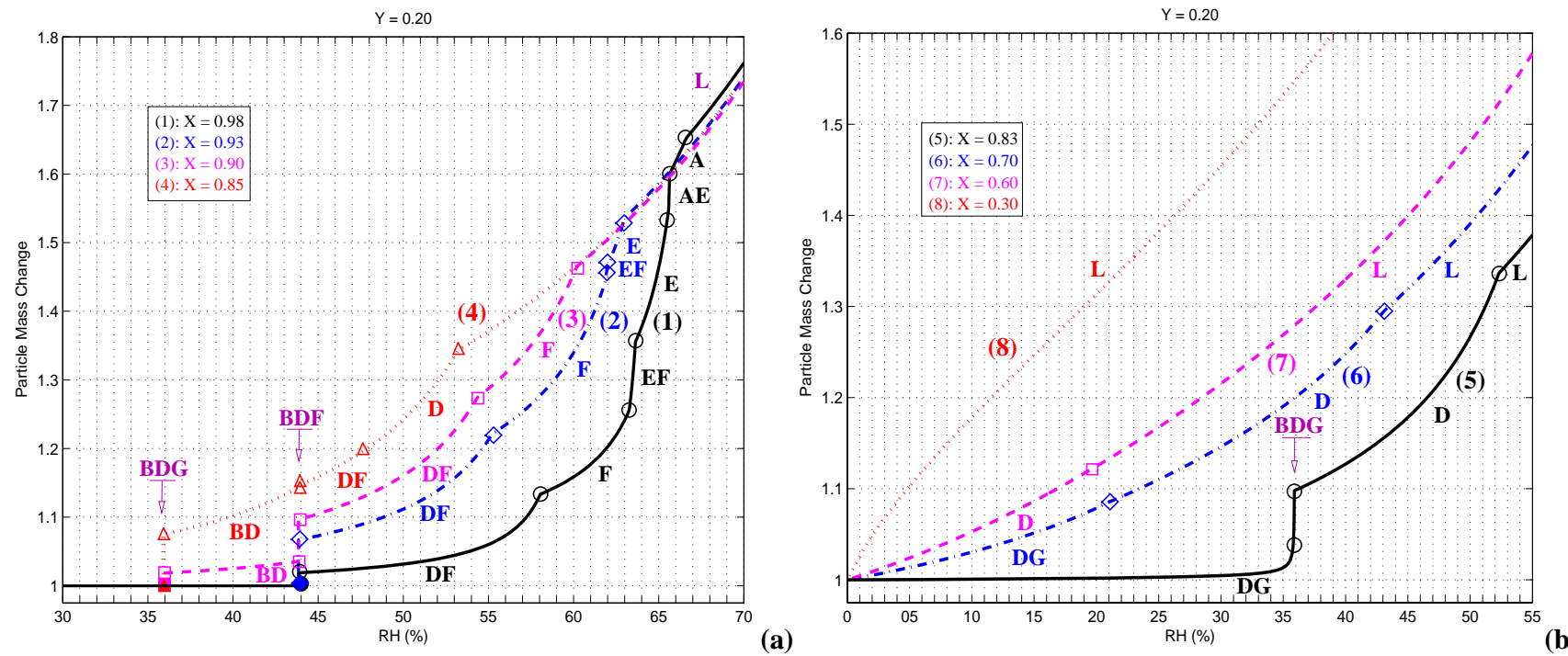

Fig. 11. Deliquescence curves for the system $\left(\mathrm{NH}_{4}\right)_{2} \mathrm{SO}_{4} / \mathrm{H}_{2} \mathrm{SO}_{4} / \mathrm{NH}_{4} \mathrm{NO}_{3} / \mathrm{HNO}_{3} / \mathrm{H}_{2} \mathrm{O}$ with the sulfate fraction $Y=0.2$ at $298.15 \mathrm{~K}$. Relative mass with changing relative humidity for several values of $X$. (a): (1) $X=0.98$, (2) $X=0.93$, (3) $X=0.9$, (4) $X=0.85$. (b): (5) $X=0.83$, (6) $X=0.7$, (7) $X=0.6,(8) X=0.3$. Curves (1) to (8) represent the relative particle mass on the vertical cuts at the corresponding $X$-values in Fig. 10b.

measurements of Martin et al. (2000) occur at supersaturated solutions that are nitrate rich. Thus, in order to apply the current model to predict crystallization behavior in a multicomponent solution, there is a need to develop/calibrate activity coefficient models that are capable to predict accurately ac- tivity coefficients of supersaturated multicomponent aqueous solutions.

Figure 13 depicts the efflorescence $R H$ for the system $\left(\mathrm{NH}_{4}\right)_{2} \mathrm{SO}_{4} / \mathrm{H}_{2} \mathrm{SO}_{4} / \mathrm{H}_{2} \mathrm{O}$ at $298.15 \mathrm{~K}$. The activity coefficient calculation is carried out using the ExUNIQUAC 


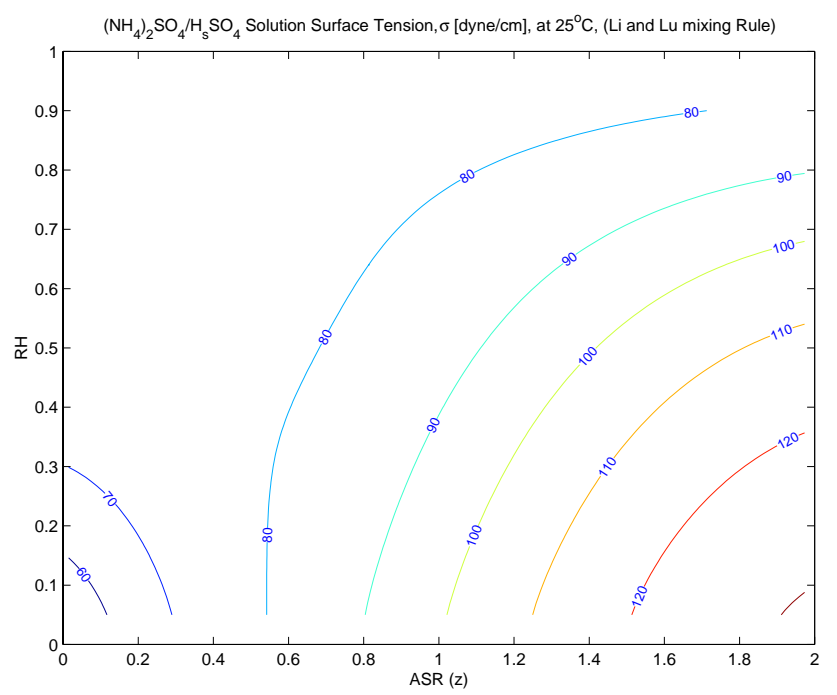

Fig. 12. Surface tension for the binary electrolyte aqueous solution $\left(\mathrm{NH}_{4}\right)_{2} \mathrm{SO}_{4} / \mathrm{H}_{2} \mathrm{SO}_{4} / \mathrm{H}_{2} \mathrm{O}$ at $298.15 \mathrm{~K}$. Labels on the contours (-) present the surface tension values $\sigma_{\text {liquid/air }}(\mathrm{dyn} / \mathrm{cm})$, computed based on Li \& Lu's mixing rule ( $\mathrm{Li}$ and $\mathrm{Lu}, 2001$ ).

model. The labeled solid lines are the efflorescence $R H$ curves that are reconstructed based on the expectation time contours of efflorescence. Labels on the contours (-) present the expectation time ( $\mathrm{min}$ ) of efflorescence in the nature logarithmic scale, $\ln \tau_{\text {nucl }}$, for AS and LET. The dotted line and dashed line are the crystallization $R H$ observations of initial crystal formation and complete crystallization, respectively, reported in Martin et al. (2003), where laboratory data of the crystallization $R H$ of particles at $293 \mathrm{~K}$ throughout the entire sulfate-nitrate-ammonium composition space are expressed as an empirical polynomial. It shall be noted that the good agreement of the predicted and observed efflorescence $R H$ in Fig. 13 is in part due to the AS and LET curves are forced, respectively, to intersect with the observation curve at $\mathrm{ASR}=2$ and 1.5. This is a result of the fact that the parameter values $\sigma_{\text {crystal/air }}$ for AS and LET in the homogeneous nucleation theory have been determined based on a measurement of the efflorescence $R H$ at these two ASR points.

It shall be also noted that the present model treats only homogeneous nucleation and, as a result, there is no possibility to predict the crystallization of ammonium bisulfate and ammonium nitrate. In contrast, the measurements of Schlenker et al. (2004) show that these salts do crystallize by heterogeneous nucleation once another crystal has formed by homogeneous nucleation. Thus, a rigorous validation of the UHAERO framework through comparisons to the experimental data of Martin et al. (2003) and Schlenker et al. (2004) in the ammonium-sulfate-nitrate space would require the treatment of heterogeneous nucleation, a topic that is be-

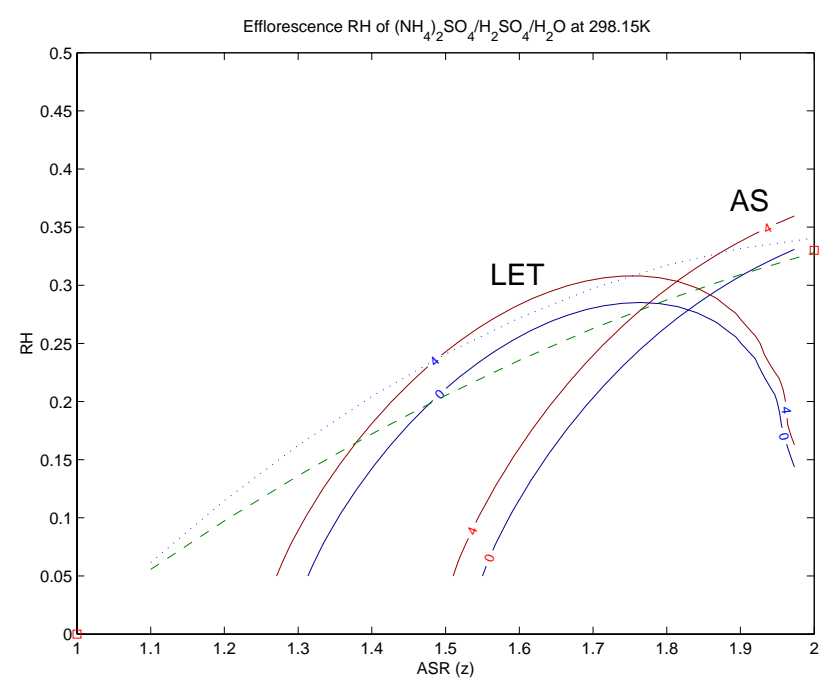

Fig. 13. Efflorescence $R H$ for the system $\left(\mathrm{NH}_{4}\right)_{2} \mathrm{SO}_{4} / \mathrm{H}_{2} \mathrm{SO}_{4} / \mathrm{H}_{2} \mathrm{O}$ at $298.15 \mathrm{~K}$. Labels on the contours (-) present the expectation time (min) of efflorescence in the nature logarithmic scale $\left(\ln \tau_{\text {nucl }}\right)$. The dotted line and dashed line are, respectively, the crystallization $R H$ observations at $293 \mathrm{~K}$ of initial crystal formation and complete crystallization (Martin et al., 2003).

yond the scope of the present paper and that will be a subject of the future research.

\section{Computational efficiency}

The initialization of UHAERO has two modes depending on the circumstance of its application: (a) a so-called cold start, in which no a priori information is available and the system is initialized as an infinitely dilute solution, or (b) a warmstart, in which a convergent solution of a neighbor state is available to initialize the system; this is the case when applying it in conjunction with a 3-D chemical transport model. The computational cost for Case (1) (i.e., the water content is specified) is estimated with the model runs for generating phase diagrams. For the contour plots (for $Y=0.85$ ) shown in Fig. 14, a uniform grid with $\frac{1}{2} n(n-1)(n=100)$ (interior) points on the unit triangle is used. When the warm start strategy is applied for the liquid-solid equilibrium calculations where the model run for the $(i, j)$ point is initialized with the solution of the $(i, j-1)$ point, the elapsed time is $0.52 \mathrm{~s}$ (or $0.20 \mathrm{~s}$ ) for 4950 UHAERO-PSC (or UHAEROExUNIQUAC) runs on a Linux PC equipped with Intel(R) Pentium(R) $43.20 \mathrm{GHz}$ processor. It requires an average 3.45 (or 3.37) Newton iterations per grid point for UHAEROPSC (or UHAERO-ExUNIQUAC) runs with a stopping criterion for convergence being that Euclidean norm of the residuals does not exceed $10^{-8}$. If a cold start is used for generating contours, the average number of Newton iterations 


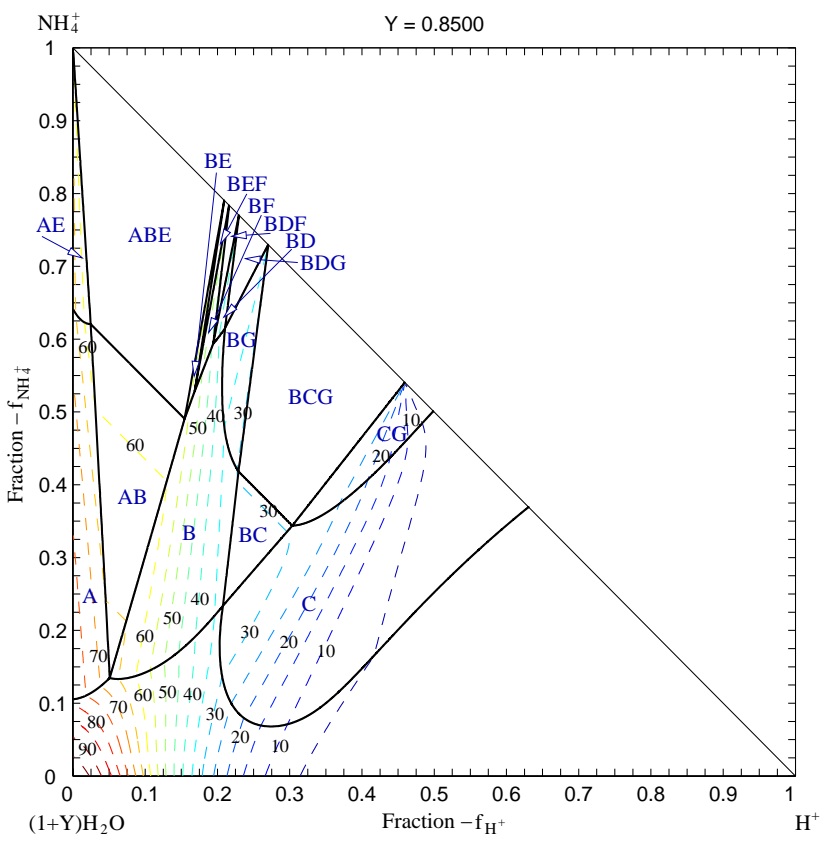

Fig. 14. Reconstruction of the phase diagram for the system $\left(\mathrm{NH}_{4}\right)_{2} \mathrm{SO}_{4} / \mathrm{H}_{2} \mathrm{SO}_{4} / \mathrm{NH}_{4} \mathrm{NO}_{3} / \mathrm{HNO}_{3} / \mathrm{H}_{2} \mathrm{O}$ with the sulfate fraction $Y=0.85$ at $298.15 \mathrm{~K}$ in the $\left(f_{\mathrm{H}^{+}}, f_{\mathrm{NH}_{4}^{+}}\right)$coordinate with tracking of the presence of each solid phases. For each region of space whose boundaries are marked with bold lines, the existing solid phases at equilibrium are represented. Labels on the contours (-) present the water activity values as a function of the fractions $f_{\mathrm{H}^{+}}$ and $f_{\mathrm{NH}_{4}^{+}}$.

per grid point required for the convergence is 15.1 (or 12.75) for UHAERO-PSC (or UHAERO-ExUNIQUAC) runs. The computational cost for Case (2) ( $R H$ is fixed) is estimated with the model runs for the generation of the contour plots in the $(X, R H)$ coordinate (for $Y=0.85)$ as shown in Fig. 4. By using a uniform grid of $(n-1) \times(n-1)$ (interior) points $(n=100)$ on the unit square and applying the same warmstart strategy, it takes $1.1 \mathrm{~s}$ (or $0.47 \mathrm{~s}$ ) for 9801 UHAEROPSC (or UHAERO-ExUNIQUAC) runs, a time that is doubled in comparison with Case (1) due to the doubling of the grid points. The average Newton iterations per grid point for the convergence solution is 3.41 (or 3.24) for UHAERO-PSC (or UHAERO-ExUNIQUAC) runs. The computation times quoted above are those for generation of the entire phase diagram of 9801 points. If implemented in a 3-D atmospheric model with, say, $50 \times 50 \times 10=25000$ grid cells, then the total computing time needed per time step for the thermodynamic calculation is estimated to be about $2.9 \mathrm{~s}$ (or $1.2 \mathrm{~s}$ ) for UHAERO-PSC (or UHAERO-ExUNIQUAC) runs. Moreover, this corresponds to a very strict convergence criterion that the Euclidean norm of the residuals is less than $10^{-8}$. The same efficiency is achieved in either mode of application; there is no need, for example, to iterate on the water content as is required in several other models.
When UHAERO is applied for the gas-aerosol equilibrium calculations, the computational time and the number of Newton iterations are slightly increased, but still are of the same order as in the case of the liquid-solid calculations. Table 2 lists the average numbers of Newton iterations per grid point for a convergence solution when applying UHAERO with various model configurations for the reconstruction of a phase diagram. Table 3 shows average CPU-times $(\mu \mathrm{s})$ per Newton iteration and average CPUpercentage per Newton iteration for activity coefficient calculations when applying UHAERO for the reconstruction of a phase diagram in both the $(X, R H)$ and $(X, Z)$ coordinates with $Y=0.85$. The calculations are performed on two different computer architectures: a Linux PC equipped with 32-bit Intel(R) Pentium(R) $43.20 \mathrm{GHz}$ processor and a Linux PC equipped with 64-bit $\mathrm{AMD}(\mathrm{R})$ Opteron(R) $2.39 \mathrm{GHz}$ processor. The CPU times of UHAERO-PSC runs are dominated by the PSC model calculations of activity coefficients and the average CPU-percentages for activity coefficient calculations range from $54.1 \%$ to $70.0 \%$. Since the ExUNIQUAC model does not consider ternary interactions, it is more efficient for activity coefficient calculations compared to the PSC model, and takes from $21.8 \%$ to $34.5 \%$ of the total CPUtimes of UHAERO-ExUNIQUAC runs. The overall CPU time of UHAERO-ExUNIQUAC is 1.7 faster than that of UHAERO-PSC for gas-aerosol equilibrium calculations; in the case of liquid-solid equilibrium calculations, a speed-up factor of 2.5 is observed. Based on the widespread application of ISORROPIA, the examination of the model performance of UHAERO against that of ISORROPIA over an extended composition, temperature, and RH domain is necessary. The performance and advantages of ISORROPIA over the usage of other thermodynamic equilibrium codes is assessed in Nenes et al. (1998); Ansari and Pandis (1999). Since the evaluation of the predictions of ISORROPIA versus those of AIM has been carried out previously and since AIM uses the same activity coefficient model as UHAEROPSC, we focus here the computing speed comparisons between UHAERO and ISORROPIA. Table 4 compares the average CPU-times ( $\mu$ s) per grid point and the average number of iterations per grid point when applying UHAERO (in the warm-start mode) and ISORROPIA for "reverse problems" on a uniform grid of $(n-1) \times(n-1)(n=100)$ (interior) points on the unit square in the $(X, R H)$ coordinate with $Y=0.85$. The calculations of "reverse problems", in which known quantities are temperature, relative humidity and the aerosol phase concentrations, are needed in detailed models of aerosol dynamics (Pilinis et al., 2000). The CPUtimes for ISORROPIA runs are measured for two different sets of convergence criteria as in Makar et al. (2003). The "High" runs use convergence criteria appropriate for applications in which accuracy is more important than the net processing time. The "Low" runs use convergence criteria appropriate for applications in which processing speed has a greater priority than the details of solution accuracy. It can be 
Table 2. Average number of Newton iterations per grid point (UHAERO) ${ }^{1}$.

\begin{tabular}{|c|c|c|c|c|c|c|c|c|}
\hline & \multicolumn{4}{|c|}{ Gas-Aerosol $^{2}$} & \multicolumn{4}{|c|}{ Liquid-Solid $^{3}$} \\
\hline & \multicolumn{2}{|c|}{ Case (1) - Fixed $Z^{4}$} & \multicolumn{2}{|c|}{ Case (2) - Fixed $R H^{5}$} & \multicolumn{2}{|c|}{ Case (1) - Fixed $Z$} & \multicolumn{2}{|c|}{ Case (2) - Fixed $R H$} \\
\hline & Cold $^{6}$ & Warm $^{7}$ & Cold & Warm & Cold & Warm & Cold & Warm \\
\hline
\end{tabular}

${ }^{1}$ UHAERO runs are performed on a Linux PC equipped with 32-bit Intel(R) Pentium(R) 4 3.20GHz processor with the PSC and ExUNIQUAC models for activity coefficient calculations.

2 Gas-Aerosol denotes UHAERO runs where gas-aerosol equilibrium problems are solved.

${ }^{3}$ Liquid-Solid denotes UHAERO runs where liquid-solid equilibrium problems are solved.

${ }^{4}$ Case (1) - Fixed $Z$ denotes UHAERO runs on a uniform grid with $\frac{1}{2} 99 \times 100$ interior points on the unit triangle in the $(X, Z)$ coordinate with $Y=0.85$.

${ }^{5}$ Case (2) - Fixed $R H$ denotes UHAERO runs on a uniform grid of $99 \times 99$ interior points on the unit square in the $(X, R H)$ coordinate with $Y=0.85$.

${ }^{6}$ Cold denotes that UHAERO runs are in the cold-start mode.

7 Warm denotes that UHAERO runs are in the warm-start mode.

${ }^{8}$ ITER / point denotes the average number of Newton iterations per grid point required for a convergence solution.

Table 3. Average CPU-times ( $\mu$ s) per Newton iteration and average CPU-percentage per Newton iteration for activity coefficient calculations $(\mathrm{UHAERO})^{1}$.

\begin{tabular}{|c|c|c|c|c|c|c|c|c|}
\hline & \multicolumn{4}{|c|}{ Gas-Aerosol $^{2}$} & \multicolumn{4}{|c|}{ Liquid-Solid $^{3}$} \\
\hline & \multicolumn{2}{|c|}{ PSC } & \multicolumn{2}{|c|}{ ExUNIQUAC } & \multicolumn{2}{|c|}{ PSC } & \multicolumn{2}{|c|}{ ExUNIQUAC } \\
\hline & $32-\mathrm{Bit}^{4}$ & $64-\mathrm{Bit}^{5}$ & 32-Bit & 64-Bit & 32-Bit & 64-Bit & 32-Bit & 64-Bit \\
\hline
\end{tabular}

${ }^{1}$ UHAERO Simulations are performed on two grids: a uniform grid of $99 \times 99$ interior points on the unit square in the $(X, R H)$ coordinate with $Y=0.85$ and a uniform grid with $\frac{1}{2} 99 \times 100$ interior points on the unit triangle in the $(X, Z)$ coordinate with $Y=0.85$.

2 Gas-Aerosol denotes that gas-aerosol equilibrium problems are solved.

${ }^{3}$ Liquid-Solid denotes that liquid-solid equilibrium problems are solved.

4 32-Bit denotes that simulations are performed on a a Linux PC equipped with 32-bit Intel(R) Pentium(R) $43.20 \mathrm{GHz}$ processor.

5 64-Bit denotes that simulations are performed on a Linux PC equipped with 64-bit AMD(R) Opteron(R) 2.39GHz processor.

${ }^{6}$ CPU/ITER denotes the average CPU-times ( $\mu$ s) per Newton iteration.

$7 \% a_{l}(\cdot)$ denotes the average CPU-percentage (per Newton iteration) for activity coefficient calculations with the PSC and ExUNIQUAC models. 
Table 4. Average CPU-times $(\mu s)$ per grid point and average number of iterations per grid point (UHAERO vs. ISORROPIA) ${ }^{1}$.

\begin{tabular}{|c|c|c|c|c|c|c|c|c|}
\hline & \multicolumn{4}{|c|}{ Liquid-Solid $^{2}$} & \multicolumn{4}{|c|}{ Liquid-Meta $^{3}$} \\
\hline & \multicolumn{2}{|c|}{ UHAERO $^{4}$} & \multicolumn{2}{|c|}{ ISORROPIA $^{5}$} & \multicolumn{2}{|c|}{ UHAERO } & \multicolumn{2}{|c|}{ ISORROPIA } \\
\hline & PSC & ExUNIQUAC & "High"6 & "Low"” & PSC & ExUNIQUAC & "High" & "Low" \\
\hline
\end{tabular}

1 Simulations are performed on a Linux PC equipped with 32-bit Intel(R) Pentium(R) $43.20 \mathrm{GHz}$ processor for "reverse problems" on a uniform grid of $99 \times 99$ interior points on the unit square in the $(X, R H)$ coordinate with $Y=0.85$.

2 Liquid-Solid denotes the model runs in which soluble salts precipitate when supersaturation occurs.

${ }^{3}$ Liquid-Meta denotes the model runs in which soluble salts do not precipitate when supersaturation occurs, and aerosol is in metastable state.

${ }^{4}$ UHAERO runs are in the warm-start mode.

5 ISORROPIA v1.6 is used.

6 "High" denotes the ISORROPIA runs that use convergence criteria appropriate for applications in which accuracy is more important than the net processing time; as in Makar et al. (2003), the convergence criteria for "High" are set to be $\mathrm{EPS}=10^{-13}$, $\mathrm{EPSACT}=10^{-6}$, MAXIT $=200$, NSWEEP $=20$, NDIV $=30$.

7 "Low" denotes the ISORROPIA runs that use convergence criteria appropriate for applications in which processing speed has a greater priority than the details of solution accuracy; as in Makar et al. (2003), the convergence criteria for "Low" are set to be EPS $=10^{-6}$, EPSACT $=5 \times 10^{-2}$, MAXIT $=100$, NSWEEP $=4$, NDIV $=4$.

$8 \mathrm{CPU} /$ point denotes the average CPU-times ( $\mu$ s) per grid point.

${ }^{9}$ ITER / point denotes the average number of iterations per grid point required for a convergence solution.

${ }^{10}$ N.A. denotes that the information is not available; extensive iterations are required for grid points in high acidic and low $R H$ regions - a convergence solution can be obtained by increasing the iteration number NSWEEP, but the CPU also increases proportionally.

observed that the overall speed of UHAERO is comparable to that of ISORROPIA, thus is appropriate for the inclusion of UHAERO in 3-D chemical transport models.

\section{Conclusions}

Aerosol thermodynamic equilibrium models are a basic component of three-dimensional atmospheric chemical transport models of aerosols. Because these equilibrium models are computationally intensive, those that are currently implemented in 3-D models incorporate a priori specification of phase behavior in order to facilitate computation. Presented here is a new inorganic aerosol thermodynamic computational model that is sufficiently numerically efficient to be included directly in 3-D atmospheric models. The model includes a first-principles calculation of deliquescence behavior. The first attempt to treat efflorescence in a thermodynamic aerosol model based on liquid-solid nucleation theory is also presented. Extensive results are presented for the phase behavior in the sulfate/nitrate/ammonium/water system, using the Pitzer-Simonson-Clegg (PSC) activity coefficient model.
Acknowledgements. This work was supported by US Environmental Protection Agency grant X-83234201. The authors thank S. L. Clegg for providing the code for the PSC model based activity coefficient calculation.

Edited by: F. J. Dentener

\section{References}

Amundson, N. R., Caboussat, A., He, J.-W., Seinfeld, J. H., and Yoo, K.-Y.: An optimization problem related to the modeling of atmospheric inorganic aerosols, C. R. Acad. Sci. Paris, Ser. I, 340, 683-686, doi:10.1016/j.crma.2005.01.025, 2005.

Amundson, N. R., Caboussat, A., He, J. W., Seinfeld, J. H., and Yoo, K. Y.: Primal-dual active-set algorithm for chemical equilibrium problems related to the modeling of atmospheric inorganic aerosols, J. Optimization Theory Appl., 128, 3, doi:10.1007/s10957-006-9030-y, 2006.

Ansari, A. S. and Pandis, S. N.: Prediction of multicomponent inorganic atmospheric aerosol behavior, Atmos. Environ., 33, 745757, doi:10.1016/S1352-2310(98)00221-0, 1999.

Bromley, L. A.: Thermodynamic properties of strong electrolytes in aqueous Solutions, AIChE Journal, 19, 313-320, 1973. 
Chen, J. P.: Theory of deliquescence and modified Kohler curves, J. Atmos. Sci., 51, 3505-3516, 1994.

Clegg, S. L. and Pitzer, K. S.: Thermodynamics of multicomponent, miscible, ionic solutions: generalized equations for symmetrical electrolytes, J. Phys. Chem., 96, 3513-3520, 1992.

Clegg, S. L., Pitzer, K. S., and Brimblecombe, P.: Thermodynamics of multicomponent, miscible, ionic solutions. Mixtures including unsymmetrical electrolytes, J. Phys. Chem., 96, 9470-9479, 1992.

Clegg, S. L., Brimblecombe, P., and Wexler, A. S.: Thermodynamic Model of the System $\mathrm{H}^{+}-\mathrm{NH}_{4}^{+}-\mathrm{SO}_{4}^{2-}-\mathrm{NO}_{3}^{-}-\mathrm{H}_{2} \mathrm{O}$ at Tropospheric Temperatures, J. Phys. Chem. A, 102, 2137-2154, 1998a.

Clegg, S. L., Brimblecombe, P., and Wexler, A. S.: Thermodynamic Model of the System $\mathrm{H}^{+}-\mathrm{NH}_{4}^{+}-\mathrm{Na}^{+}-\mathrm{SO}_{4}^{2-}-\mathrm{NO}_{3}^{-}-\mathrm{Cl}^{-}-\mathrm{H}_{2} \mathrm{O}$ at $298.15 \mathrm{~K}$, J. Phys. Chem. A, 102, 2155-2171, 1998b.

Clegg, S. L., Seinfeld, J. H., and Edney, E. O.: Thermodynamic modelling of aqueous aerosols containing electrolytes and dissolved organic compounds. II. An extended ZdanovskiiStokes-Robinson approach, J. Aerosol Sci., 34, 667-690, doi:10.1016/S0021-8502(03)00019-3, 2003.

Cohen, M. D., Flagan, R. C., and Seinfeld, J. H.: Studies of Concentrated Electrolyte Solutions Using the Electrodynamic Balance. 3. Solute Nucleation, J. Phys. Chem., 91, 4583-4590, 1987.

$\mathrm{Hu}, \mathrm{Y}$. F. and Lee, H.: Prediction of the surface tension of mixed electrolyte solutions based on the equation of Patwardhan and Kumar and the fundamental Butler equations, J. Colloid Interface Sci., 269, 442-448, 2004.

Jacobson, M., Tabazadeh, A., and Turco, R.: Simulating equilibrium within aerosols and nonequilibrium between gases and aerosols, J. Geophys. Res., 101, 9079-9091, 1996.

Jacobson, M. Z.: Studying the effects of calcium and magnesium on size-distributed nitrate and ammonium with EQUISOLV II, Atmos. Environ., 30, 3635-3649, 1999.

Kim, Y. P. and Seinfeld, J. H.: Atmospheric Gas-Aerosol Equilibrium III. Thermodynamics of Crustal Elements $\mathrm{Ca}^{2+}, \mathrm{K}^{+}$, and $\mathrm{Mg}^{2+}$, Aerosol Sci. Technol., 22, 93-110, 1995.

Kim, Y. P., Seinfeld, J. H., and Saxena, P.: Atmospheric gas-aerosol equilibrium I. Thermodynamic model, Aerosol Sci. Technol., 19, 157-181, 1993a.

Kim, Y. P., Seinfeld, J. H., and Saxena, P.: Atmospheric GasAerosol Equilibrium II. Analysis of Common Approximations and Activity Coefficient Calculation Methods, Aerosol Sci. Technol., 19, 182-198, 1993b.

Korhonen, P., Laaksonen, A., Batris, E., and Viisanen, Y.: Thermodynamics for highly concentrated water - ammonium sulfate solutions, J. Aerosol Sci., 29, S379-S380, 1998.

Kusik, C. L. and Meissner, H. P.: Electrolyte activity coefficients in inorganic processing, AIChE Symposium Series, 173, 14-20, 1978.

Li, Z. and Lu, B. C.: Surface tension of aqueous electrolyte solutions at high concentrations - representation and prediction, Chem. Eng. Sci., 56, 2879-2888, 2001.

Li, Z. B., Li, Y. G., and Lu, J. F.: Surface tension model for concentrated electrolyte aqueous solutions by the Pitzer equation, Ind. Eng. Chem. Res., 33, 1133-1139, 1999.

Makar, P. A., Bouchet, V. S., and Nenes, A.: Inorganic chemistry calculations using HETV - vectorized solver for $\mathrm{SO}_{4}^{2-} / \mathrm{NO}_{3}^{-} / \mathrm{NH}_{4}^{+}$system based on the ISOR-
ROPIA algorithms, Atmos. Environ., 37(16), 2279-2294, doi:10.1016/S1352-2310(03)00074-8, 2003.

Martin, M., George, G., and Mirabel, P.: Densities and Surface tensions of $\mathrm{H}_{2} \mathrm{SO}_{4} / \mathrm{HNO}_{3} / \mathrm{H}_{2} \mathrm{O}$ solution, Geophys. Res. Lett., 27, 197-200, 2000.

Martin, S. T.: Phase Transitions of Aqueous Atmospheric Particles, Chem. Rev., 100, 3403-3454, doi:10.1021/cr990034t, 2000.

Martin, S. T., Schlenker, J. C., Malinowski, A., Hung, H.M., and Rudich, Y.: Crystallization of atmospheric sulfatenitrate-ammonium particles, Geophys. Res. Lett., 30, 2102, doi:10.1029/2003GL017930, 2003.

Martin, S. T., Hung, H.-M., Park, R. J., Jacob, D. J., Spurr, R. J. D., Chance, K. V., and Chin, M.: Effects of the physical state of tropospheric ammonium-sulfate-nitrate particles on global aerosol direct radiative forcing, Atmos. Chem. Phys., 4, 183-214, 2004.

Meng, Z. Y., Seinfeld, J. H., Saxena, P., and Kim, Y. P.: Atmospheric Gas-Aerosol Equilibrium IV. Thermodynamics of Carbonates, Aerosol Sci. Technol., 23, 131-154, 1995.

Metzger, S., Dentener, F., Pandis, S., and Lelieveld, J.: Gas/aerosol partitioning: 1. A computationally efficient model, J. Geophys. Res., 107(D16), 4312, doi:10.1029/2001JD001102, 2002.

Nenes, A., Pandis, S. N., and Pilinis, C.: ISORROPIA: A new thermodynamic equilibrium model for multiphase multicomponent inorganic aerosols, Aquatic Geochemistry, 4, 123-152, 1998.

Pilinis, C., Capaldo, K. P., Nenes, A., and Pandis, S. N.: MADM - a new multicomponent aerosol dynamics model, Aerosol Sci. Tech., 32(5), 482-502, 2000.

Pitzer, K. S.: Thermodynamics of electrolytes 1 . Theoretical basis and general equations, J. Phys. Chem., 77, 268-277, 1973.

Pitzer, K. S.: Thermodynamics of electrolytes 5. Effects of higherorder electrostatic terms, J. Solution Chem., 4, 249-265, 1975.

Pitzer, K. S. and Mayorga, G.: Thermodynamics of electrolytes 2. Activity and osmotic coefficients for strong electrolytes with one or both ions univalent, J. Phys. Chem., 77, 2300-2308, 1973.

Pitzer, K. S. and Simonson, J. M.: Thermodynamics of Multicomponent, Miscible, Ionic Systems: Theory and Equations, J. Phys. Chem., 90, 3005-3009, 1986.

Potukuchi, S. and Wexler, A. S.: Identifying solid-aqueous-phase transitions in atmospheric aerosols. II. Acidic solutions, Atmos. Environ., 29, 3357-3364, doi:10.1016/1352-2310(95)00212-H, 1995.

Schlenker, J. C., Malinowski, A., Martin, S. T., Hung, H., and Rudich, Y.: Crystals formed at $293 \mathrm{~K}$ by aqueous sulfate-nitrateammonium-proton aerosol particles, J. Phys. Chem., 108, 93759383, 2004.

Seinfeld, J. H. and Pandis, S. N.: Atmospheric Chemistry and Physics: From Air Pollution to Climate Change, Wiley, New York, 1998.

Stokes, R. H. and Robinson, R. A.: Interactions in aqueous nonelectrolyte solutions, I. Solute-solvent equilibria, J. Phys. Chem., 70, 2126-2131, 1966.

Tang, I. N. and Munkelwitz, H. R.: Water activities, densities, and refractive indices of aqueous sulfates and sodium nitrate droplets of atmospheric importance, J. Geophys. Res., 99, 18 801-18 808, 1994.

Thomsen, K. and Rasmussen, P.: Modeling of vapor-liquid-solid equilibrium in gas-aqueous electrolyte systems, Chem. Eng. Sci., 54, 1787-1802, 1999. 
Topping, D. O., McFiggans, G. B., and Coe, H.: A curved multicomponent aerosol hygroscopicity model framework: Part 1 - Inorganic compounds, Atmos. Chem. Phys., 5, 1205-1222, 2005.

Trebs, I., Metzger, S., Meixner, F. X., Helas, G., Hoffer, A., Rudich, Y., Falkovich, A. H., Moura, M. A. L., da Silva, R. S., Artaxo, P., Slanina, J., Andreae, M. O.: The $\mathrm{NH}_{4}^{+}-\mathrm{NO}_{3}^{-}-\mathrm{Cl}^{-}-\mathrm{SO}_{4}^{2-}$ $\mathrm{H}_{2} \mathrm{O}$ aerosol system and its gas phase precursors at a pasture site in the Amazon Basin: How relevant are mineral cations and soluble organic acids? J. Geophys. Res., 110, D07303, doi:10.1029/2004JD005478, 2005

Wexler, A. S. and Clegg, S. L.: Atmospheric aerosol models for systems including the ions $\mathrm{H}^{+}, \mathrm{NH}_{4}^{+}, \mathrm{Na}^{+}, \mathrm{SO}_{4}^{2-}$, $\mathrm{NO}_{3}^{-}, \mathrm{Cl}^{-}, \mathrm{Br}^{-}$, and $\mathrm{H}_{2} \mathrm{O}$, J. Geophys. Res., 107, 4207, doi:10.1029/2001JD000451, 2002.
Zaveri, R. A., Easter, R. C., and Peters, L. K.: A computationally efficient Multicomponent Equilibrium Solver for Aerosols (MESA), J. Geophys. Res., 110, D24203, doi:10.1029/2004JD005618, 2005a.

Zaveri, R. A., Easter, R. C., and Wexler, A. S.: A new method for multicomponent activity coefficients of electrolytes in aqueous atmospheric aerosols, J. Geophys. Res., 110, D02201, doi:10.1029/2004JD004681, 2005b.

Zhang, Y., Seigneur, C., Seinfeld, J. H., Jacobson, M., Clegg, S. L., and Binkowski, F. S.: A comparative review of inorganic aerosol thermodynamic equilibrium modules: similarities, differences, and their likely causes, Atmos. Environ., doi:10.1016/S13522310(99)00236-8, 2000. 